\title{
Global modeling of SOA: the use of different mechanisms for aqueous-phase formation
}

\author{
G. Lin ${ }^{1}$, S. Sillman ${ }^{1}$, J. E. Penner ${ }^{1}$, and A. Ito ${ }^{2}$ \\ ${ }^{1}$ Department of Atmospheric, Oceanic, and Space Sciences, University of Michigan, Ann Arbor, Michigan, USA \\ ${ }^{2}$ Research Institute for Global Change, JAMSTEC, Yokohama, Kanagawa, 236-0001, Japan \\ Correspondence to: G. Lin (gxlin@umich.edu)
}

Received: 2 November 2013 - Published in Atmos. Chem. Phys. Discuss.: 12 November 2013

Revised: 11 April 2014 - Accepted: 17 April 2014 - Published: 4 June 2014

\begin{abstract}
There is growing interest in the formation of secondary organic aerosol (SOA) through condensed aqueousphase reactions. In this study, we use a global model (IMPACT) to investigate the potential formation of SOA in the aqueous phase. We compare results from several multiphase process schemes with detailed aqueous-phase reactions to schemes that use a first-order gas-to-particle formation rate based on uptake coefficients. The predicted net global SOA production rate in cloud water ranges from $13.1 \mathrm{Tg} \mathrm{yr}^{-1}$ to $46.8 \mathrm{Tg} \mathrm{yr}^{-1}$ while that in aerosol water ranges from $-0.4 \mathrm{Tg} \mathrm{yr}^{-1}$ to $12.6 \mathrm{Tg} \mathrm{yr}^{-1}$. The predicted global burden of SOA formed in the aqueous phase ranges from $0.09 \mathrm{Tg}$ to $0.51 \mathrm{Tg}$. A sensitivity test to investigate two representations of cloud water content from two global models shows that increasing cloud water by an average factor of 2.7 can increase the net SOA production rate in cloud water by a factor of 4 at low altitudes (below approximately $900 \mathrm{hPa}$ ). We also investigated the importance of including dissolved Fe chemistry in cloud water aqueous reactions. Adding these reactions increases the formation rate of aqueous-phase $\mathrm{OH}$ by a factor of 2.6 and decreases the amount of global aqueous SOA formed by $31 \%$. None of the mechanisms discussed here is able to provide a best fit for all observations. Rather, the use of an uptake coefficient method for aerosol water and a multi-phase scheme for cloud water provides the best fit in the Northern Hemisphere and the use of multiphase process scheme for aerosol and cloud water provides the best fit in the tropics. The model with Fe chemistry underpredicts oxalate measurements in all regions. Finally, the comparison of oxygen-to-carbon $(\mathrm{O} / \mathrm{C})$ ratios estimated in the model with those estimated from measurements shows that the modeled
\end{abstract}

SOA has a slightly higher $\mathrm{O} / \mathrm{C}$ ratio than the observed SOA for all cases.

\section{Introduction}

Secondary organic aerosol (SOA) has been shown to be an important component of non-refractory submicron aerosol in the atmosphere (Zhang et al., 2007; Jimenez et al., 2009). SOA is known to form from the gas-particle partitioning of semi-volatile organic compounds produced by gas-phase photochemistry (Pankow, 1994; Odum et al., 1996). However, models that only include this SOA formation mechanism typically underestimate the SOA mass as well as the oxygen-to-carbon (O/C) ratio (e.g., DeGouw et al., 2005; Heald et al., 2005; Volkamer et al., 2006; Dzepina et al., 2009). In addition, the observed $\mathrm{O} / \mathrm{C}$ ratios in aged ambient organic aerosol $(\mathrm{OA})$ cannot be explained using measured $\mathrm{O} / \mathrm{C}$ ratios in dry smoke chamber experiments (Aiken et al., 2008; $\mathrm{Ng}$ et al., 2010). One method that has been used to help close the gap between measured and modeled SOA is a refined treatment for primary organic aerosol (POA) that allows them to evaporate and further oxidize (Robinson et al., 2007; Pye and Seinfeld, 2010; Hodzic et al., 2010; LeeTaylor et al., 2011). However, there are large uncertainties in how to treat the evaporation rate as well as the oxidation mechanism for POA and thus the SOA yield from this source (Pye and Seinfeld, 2010; Spracklen et al., 2011).

Aqueous-phase processing, as a complementary pathway to gas-particle partitioning of semi-volatile and low volatility gases, has the potential to enhance both SOA mass and the $\mathrm{O} / \mathrm{C}$ ratio in atmospheric $\mathrm{OA}$. Water-soluble and polar gases 
are taken up by the aqueous phase and can be oxidized in water thereby leading to the production of low volatility substances (e.g., organic acids and especially their corresponding salts, oligomers, and organosulfates) (Blando and Turpin, 2000; Warneck, 2003; Liggio et al., 2005; Sorooshian et al., 2007; Tan et al., 2009). These low-volatility products predominately stay in the particle phase after water evaporation (Blando and Turpin, 2000; El Haddad et al., 2009) and tend to have higher $\mathrm{O} / \mathrm{C}$ ratios than those that form in gas-phase reactions (Herrmann et al., 2005; Lim et al., 2010; Ervens and Volkamer, 2010). This is because the precursors for the aqueous-phase reactions tend to be small compounds with low molecular weight (MW) that already have high $\mathrm{O} / \mathrm{C}$ ratios, and the aqueous oxidation of these small compounds either tends to add $\mathrm{O}$-containing functional groups to $\mathrm{C}-\mathrm{C}$ bonds (thereby forming higher $\mathrm{O} / \mathrm{C}$ ratio dicarboxylic acids) or to react with themselves to keep the same carbon structure and the same $\mathrm{O} / \mathrm{C}$ ratio (thereby forming oligomers) (Ervens et al., 2011).

Laboratory studies have shown that aqueous-phase reactions can produce $\mathrm{SOA}$ from $\mathrm{C} 2$ and $\mathrm{C} 3$ carbonyl compounds including glyoxal, methylglyoxal, glycolaldehyde, pyruvic acid, and acetic acid (Ervens et al., 2003; Carlton et al., 2006, 2007; Altieri et al., 2008; Perri et al., 2009; Tan et al., 2009, 2010, 2012; Lim et al., 2010). The major products from the oxidation of these carbonyl compounds are carboxylic acids, of which the most abundant is oxalic acid. Oxalic acid is also observed to be part of the aerosol emitted in biomass burning (Kundu et al., 2010) and is observed to be formed from the photochemical ageing of OA (Eliason et al., 2003). In contrast to reactions in cloud water, the major products formed from the reactions of $\mathrm{C} 2$ and $\mathrm{C} 3$ carbonyl compounds in aerosol water are oligomers (Ervens and Volkamer, 2010; Lim et al., 2010).

To date several models have been developed to estimate the amount of SOA formed in the aqueous phase (denoted aqSOA hereafter). Chen et al. (2007) used a box model to investigate the formation of SOA from aqueous-phase reactions in cloud water using an explicit aqueous mechanism that included organic acid formation from glyoxal and methylglyoxal; they found that aqueous-phase processing increased the SOA concentration by $27 \%$ for a rural scenario and by $7 \%$ for an urban scenario. Carlton et al. (2008) used a simplified mechanism with a fixed yield of $4 \%$ for the conversion of glyoxal to aqSOA in a regional air quality model. The model's ability to predict the concentration of water soluble organic carbon (WSOC) from aircraft measurements over the northeastern US was improved and the bias between predicted SOA mass and observations was decreased from $-64 \%$ to $-15 \%$. Myriokefalitakis et al. (2011) and Liu et al. (2012) employed a global model to study the formation of SOA in clouds and found that the global production rate could be $13-30 \mathrm{Tg} \mathrm{yr}^{-1}$. The contribution of aerosol water to the formation of aqueous-phase SOA from glyoxal and methylglyoxal has also been estimated in global models (Fu et al., 2008, 2009; Stavrakou et al., 2009; Lin et al., 2012). The amount of irreversible uptake of glyoxal and methylglyoxal into aerosol water was predicted to be much smaller than that in cloud droplets, when the same reactive uptake parameter $\left(\gamma=2.9 \times 10^{-3}\right)$ was used (Fu et al., 2008, 2009). This result was confirmed by Lin et al. (2012) using the same basic approach. Stavrakou et al. (2009), however, concluded that the source of SOA over the continents from uptake of glyoxal by aerosol particles was at least as large as that from cloud droplets or even up to $60 \%$ larger. These authors implemented an in-cloud formation parameterization similar to Ervens et al. (2008) rather than using an uptake formation scheme as in Fu et al. $(2008,2009)$ and Lin et al. (2012).

Uncertainties in the formation of aqSOA stem from uncertainties in how to treat its formation rate. The use of a single reactive uptake parameter $\gamma$ in aqSOA formation as in $\mathrm{Fu}$ et al. $(2008,2009)$ and Lin et al. (2012) implies a surfacelimited uptake process, but Ervens and Volkamer (2010) found no correlation between the SOA volume increase and the seed aerosol surface area for most of the seed aerosols used in the laboratory study by Volkamer et al. (2009). Instead, the SOA volume increase was shown to be linear in the total water mass on these seed particles, implying that SOA was formed as a result of a bulk process. On the other hand, the positive correlation between the SOA volume increase and the surface area observed for mixed sulfate/fulvic acid seed particles in the study by Ervens and Volkamer (2010) suggests that a surface process dominated the formation on these mixed particles. Waxman et al. (2013) also found that a surface limited uptake process could explain the observed gas-phase glyoxal mass in Mexico City. Finally, the use of an identical reactive uptake parameter for both cloud droplets and aerosol water, as in Fu et al. (2008) does not account for differences in the chemistry of carbonyl compounds between cloud water and aerosol water (Lim et al., 2010; Ervens and Volkamer, 2010).

Other uncertainties in treating the formation of aqSOA include the treatment of aqueous chemistry as well as the amount of cloud water represented in a model. Fe chemistry in cloud water has been shown to be a major source of aqueous OH (Ervens et al., 2003; Deguillaume et al., 2005), which is known to initiate the oxidation of glyoxal and methylglyoxal. However, no model, to our knowledge, has included the oxidation of $\mathrm{Fe}$ in simulating the formation of aqSOA in cloud water. In addition, the amount of cloud water in a model can influence SOA production rates (Liu et al., 2012; He et al., 2013).

In this paper, we focus on the aqueous formation of SOA from $\mathrm{C} 2$ and $\mathrm{C} 3$ carbonyl compounds not only because they are highly water soluble but also because most of the existing laboratory studies use these compounds as surrogates to examine aqueous SOA formation, so that sufficient information exists to derive their reaction mechanisms. We use a 3-D chemical transport model to test three representations of aqueous chemistry leading to SOA formation: two detailed 
mechanisms using explicit multi-phase gas/aqueous-phase chemical mechanisms and a parameterized surface-limited uptake mechanism using a reactive uptake parameter $\gamma$ to simulate the formation of aqSOA in both cloud water and aerosol water. We also examine the use of aqueous $\mathrm{Fe}$ chemistry in cloud water and the effect of changing the cloud water amount within the model.

This paper is organized as follows. The model and chemistry are described in Sect. 2. Global budgets and distributions of aqSOA predicted from a base mechanism are analyzed in Sect. 3. The change in global budgets of aqSOA resulting from four other mechanisms and one different cloud field are also analyzed in Sect. 3. We compare the simulations with available measurements in Sec. 4. Finally, Sect. 5 summarizes our conclusions.

\section{Model description}

We used the IMPACT chemical transport model (Penner et al., 1998; Liu and Penner, 2002; Liu et al., 2005; Ito et al., 2007; Feng and Penner, 2007; Wang et al., 2009; Xu and Penner, 2012; Lin et al., 2012) to simulate the formation of SOA. The IMPACT model includes the microphysics of sulfate aerosol and the interactions between sulfate and nonsulfate aerosols based on the aerosol module developed by Herzog et al. (2004) (Liu et al., 2005). Some versions include the formation of nitrate and ammonium aerosols as well, but here we extended the sulfate microphysics module initially described by Liu et al. (2005) to include the formation of SOA (Lin et al., 2012). SOA is assumed to have a log-normal size distribution with a mode radius of $0.0774 \mu \mathrm{m}$ and a geometric standard deviation of 1.402. It becomes mixed with sulfate through the condensation of gas-phase sulfuric acid, through coagulation with pure sulfate aerosols, and through aqueous formation of sulfate. We used the 1997 meteorological fields from the National Aeronautics and Space Administration (NASA) Data Assimilation Office (DAO) GEOSSTRAT model (Coy and Swinbank, 1997; Coy et al., 1997) as input to the chemical transport model. The meteorology was defined on a $4^{\circ}$ latitude $\times 5^{\circ}$ longitude horizontal grid with 46 vertical layers. Cloud water content was not available from the meteorological fields, and thus was diagnosed with a parameterization used in the National Center for Atmospheric Research Community Climate Model version 2 (NCAR CCM2) (Hack, 1998). The large scale stratiform cloud fraction was determined based on the grid box mean relative humidity $(\mathrm{RH})$ as calculated from the DAO meteorological data using the parameterization by Sundqvist et al. (1989). The convective cloud fraction was parameterized by using the convective mass flux (Xu and Krueger, 1991). The model was run for a 1 year time period with a 1 month spin-up time. Global emissions of gases, aerosols, and aerosol precursors and treatments of dry and wet deposition used here are the same as those used in Lin et al. (2012).

\subsection{SOA formation through gas-particle partitioning in the gas phase}

In this paper, we adopted the gas-particle partitioning mechanism for SOA formation described by Lin et al. (2012). Lin et al. (2012) use a fully explicit gas-phase photochemical mechanism to predict the formation of semi-volatile organic compounds (SVOCs) which then partition to an aerosol phase. These condensed SVOCs were assumed to further undergo aerosol phase reactions to form oligomers with an assumed time constant (nominally 1 day). In addition, we also accounted for SOA formation due to heterogeneous reactions of epoxides on the surface of wet sulfate aerosol by assuming an uptake coefficient of 0.0029 , the value measured for glyoxal by Liggio et al. (2005). Lin et al. (2012) explored the effect of $\mathrm{OH}$ recycling in the oxidation of isoprene on the formation of SOA using three different gas-phase chemical mechanisms. Here, we used Simulation C in Table 1 in Lin et al. (2012), since this mechanism was shown to best capture the observations of $\mathrm{OH}$ and the first generation products of isoprene-OH reactions. The mechanism includes the formation of epoxide proposed by Paulot et al. (2009), while $\mathrm{HO}_{\mathrm{x}}$ regeneration followed Peeters et al. (2009) but with a reduced rate for the $1,5-\mathrm{H}$ and $1,6-\mathrm{H}$ shifts in isoprene radicals by a factor of 10 . The basic photochemistry of $\mathrm{O}_{3}, \mathrm{OH}$, $\mathrm{NO}_{\mathrm{x}}$ and the oxidation of other volatile organic compounds (VOCs) utilized the chemical mechanism published by Ito et al. (2007).

\subsection{SOA formation in the aqueous phase}

In the presence of cloud droplets or aqueous particles, watersoluble gases (e.g., glyoxal, methylglyoxal, and glycolaldehyde) will dissolve in the aqueous phase and be further oxidized by $\mathrm{OH}$ and $\mathrm{NO}_{3}$ radicals to form products with lower volatility (e.g., dicarboxylic acids and oligomers) (Ervens et al., 2011; Lim et al., 2010). These low volatility products are assumed to remain entirely in the particulate phase as SOA when water is evaporated. In this paper, five aqSOA components are predicted: glyoxylic acid, pyruvic acid, oxalic acid, and two classes of oligomers formed from glyoxal and methylglyoxal.

\subsubsection{Multiphase reaction scheme}

The change of aqueous and gas-phase species due to the photochemical reactions and the exchange between the gas and aqueous phase are expressed by the following equations:

$$
\begin{aligned}
& \frac{\mathrm{d} C_{\mathrm{g}}}{\mathrm{d} t}=P_{\mathrm{g}}-\left(L_{\mathrm{g}}+k_{t} Q\right) C_{\mathrm{g}}+\frac{k_{t}}{H R T} C_{\mathrm{a}}, \\
& \frac{\mathrm{d} C_{\mathrm{a}}}{\mathrm{d} t}=P_{\mathrm{a}}+k_{t} Q C_{\mathrm{g}}-\left(L_{\mathrm{a}}+\frac{k_{t}}{H R T}\right) C_{\mathrm{a}},
\end{aligned}
$$

where $C_{\mathrm{a}}$ and $C_{\mathrm{g}}$ are aqueous and gas-phase concentrations (molecules $\mathrm{cm}^{-3}$ air), $P_{\mathrm{a}}$ and $P_{\mathrm{g}}$ are aqueous and gas-phase 
Table 1. Case descriptions.

\begin{tabular}{|c|c|c|c|c|}
\hline Case name & SOA formation in cloud water & SOA formation in aerosol water & Cloud field & $\begin{array}{l}\mathrm{Fe} \\
\text { chemistry }\end{array}$ \\
\hline Case 1 & $\begin{array}{l}\text { Multiphase reaction scheme is } \\
\text { used to predict carboxylic acids } \\
\text { and a kinetic approach is used } \\
\text { for all gas-particle transfer. } \\
\text { Aqueous-phase reactions of or- } \\
\text { ganics are adopted from Ja- } \\
\text { cob (1986), Pandis and Seinfeld } \\
\text { (1989), Lim et al. (2005), Her- } \\
\text { rmann (2003), and Herrmann et } \\
\text { al. (2005) (Table S3 in the Sup- } \\
\text { plement) }\end{array}$ & $\begin{array}{l}\text { Multiphase reaction scheme is } \\
\text { used to predict carboxylic acids } \\
\text { with the same aqueous-phase } \\
\text { reactions and gas-particle } \\
\text { transfer as in cloud water. } \\
\text { Surface-limited uptake process } \\
\text { is used to predict oligomers } \\
\text { with a reactive uptake pa- } \\
\text { rameter of } 3.3 \times 10^{-3} \text { for } \\
\text { glyoxal and } 2.9 \times 10^{-5} \text { for } \\
\text { methylglyoxal }\end{array}$ & $\begin{array}{l}\text { The diagnostic } \\
\text { cloud field* }\end{array}$ & N/A \\
\hline Case 2 & The same as in Case 1 & $\begin{array}{l}\text { Multiphase reaction scheme is } \\
\text { used with the aqueous-phase re- } \\
\text { actions proposed by Ervens and } \\
\text { Volkamer (2010) (Table S4 in } \\
\text { the Supplement) }\end{array}$ & $\begin{array}{l}\text { The diagnostic } \\
\text { cloud field* }\end{array}$ & N/A \\
\hline Case 3 & $\begin{array}{l}\text { Multiphase reaction scheme is } \\
\text { used with the detailed chem- } \\
\text { istry of Lim et al. (2010) (Ta- } \\
\text { ble S5 in the Supplement) }\end{array}$ & $\begin{array}{l}\text { Multiphase reaction scheme is } \\
\text { used with the detailed chem- } \\
\text { istry of Lim et al. (2010) (Ta- } \\
\text { ble S5 in the Supplement) }\end{array}$ & $\begin{array}{l}\text { The diagnostic } \\
\text { cloud field* }\end{array}$ & N/A \\
\hline Case 4 & The same as in Case 1 & The same as in Case 1 & $\begin{array}{l}\text { GFDL AM3 } \\
\text { cloud field }\end{array}$ & N/A \\
\hline Case 5 & $\begin{array}{l}\text { The same as in Case } 1 \text {, but in- } \\
\text { cluding aqueous Fe chemistry } \\
\text { in cloud water (Table S6 in the } \\
\text { Supplement) }\end{array}$ & The same as in Case 1 & $\begin{array}{l}\text { The diagnostic } \\
\text { cloud field* }\end{array}$ & $\begin{array}{l}\text { Includes } \\
\text { aqueous } \mathrm{Fe} \\
\text { chemistry }\end{array}$ \\
\hline Case 6 & $\begin{array}{l}\text { Surface-limited uptake process } \\
\text { is used with a reactive up- } \\
\text { take parameter of } 2.9 \times 10^{-3} \\
\text { for both glyoxal and methylgly- } \\
\text { oxal }\end{array}$ & $\begin{array}{l}\text { Surface-limited uptake process } \\
\text { is used with a reactive up- } \\
\text { take parameter of } 2.9 \times 10^{-3} \\
\text { for both glyoxal and methylgly- } \\
\text { oxal }\end{array}$ & $\begin{array}{l}\text { The diagnostic } \\
\text { cloud field* }\end{array}$ & N/A \\
\hline
\end{tabular}

* The diagnostic cloud field used the parameterization for cloud water published by Hack (1998).

chemical production rates (molecules $\mathrm{cm}^{-3}$ air s${ }^{-1}$ ), $L_{\mathrm{a}}$ and $L_{\mathrm{g}}$ are aqueous and gas-phase pseudo-first-order chemical loss rates $\left(\mathrm{s}^{-1}\right), H$ is the Henry's law coefficient $\left(\mathrm{M} \mathrm{atm}^{-1}\right)$, $R$ is the universal gas constant $\left(\mathrm{Latm} \mathrm{mol}^{-1} \mathrm{~K}^{-1}\right), T$ is the temperature $(\mathrm{K}), Q$ is the liquid water content $\left(\mathrm{cm}^{3}\right.$ $\mathrm{H}_{2} \mathrm{O} \mathrm{cm}^{-3}$ air), and $k_{t}\left(\mathrm{~cm}^{3}\right.$ air cm $\left.{ }^{-3} \mathrm{H}_{2} \mathrm{O} \mathrm{s}^{-1}\right)$ is a firstorder rate constant that represents diffusion through the gas phase and across the interface of the drop (see Schwartz (1986) and Lelieveld and Crutzen (1991) for details).

We used the method described by Sillman et al. (2007) to solve Eq. (1a) and (1b). This method is based on the implicit (reverse Euler) equations but incorporates a number of nonstandard treatments as described in Sillman (1991) and Barth et al. (2003). The mass transfer rate across the gas-aqueous interface is assumed to be limited by diffusion and is determined for each gas by its molecular diffusion, mass accommodation coefficient and Henry's law constant (Lelieveld and Crutzen, 1991). Since not all gas diffusivities are known, we used a single gas diffusivity of $0.1 \mathrm{~cm}^{2} \mathrm{~s}^{-1}$ for all gaseous species. This is unlikely to add a large uncertainty since the values of available gas diffusivities do not differ by much from the value we used here (Schwartz, 1986; Lelieveld and Crutzen, 1991). Accommodation coefficients for each species are listed in Table S7 in the Supplement and assumed to be 0.05 for species for which no information is available. For situations in which the average concentration of an aqueous species is limited by the rate of diffusion within the aqueous phase, the average aqueousphase concentration is scaled to the surface concentration by the factor $Q$ defined in Eq. (2.14) in Lelieveld and Crutzen 
(1991). In addition, an effective cloud droplet radius of $10 \mu \mathrm{m}$ is assumed for all clouds. Aqueous reactions in aerosol water only take place in the 2 pure sulfate modes within the model, while the effective radius for aqueous sulfate particles (the ratio of third to second moment of the wet sulfate aerosol size distributions) is calculated explicitly according to the relative humidity-dependent size. Aerosol water was calculated based on the amount of water uptake for the modeled pure sulfate particles, which is based on Köhler theory (Ghan and Zaveri, 2007) using the RH and hygroscopicity of sulfate to calculate the wet volume mean radius from the dry volume mean radius of each mode. This formulation limits the aqueous SOA formation in aerosols to only include situations in which the deliquescence relative humidity (DRH) for pure sulfate aerosol (set to 0.8 ) has been reached. We note that the DRH would decrease in mixed sulfate and SOA particles (Brooks et al., 2002; Smith et al., 2012). Thus, the assumption that aqSOA only forms in the pure sulfate aerosols within the model, and the use of 0.80 as the DRH may underestimate the formation of aqSOA to some extent. In addition, water uptake by OA was not treated. There are two reasons for this assumption. First, the reactive uptake parameter $(\gamma=0.0029)$ for glyoxal that is used for one of the mechanisms studied here was observed for wet sulfate aerosol only (Liggio et al., 2005). Second, OA is less hygroscopic than sulfate, and the uncertainty associated with neglecting the contribution of OA water is expected to be less than uncertainties caused by the observed range of reactive uptake coefficients and the photochemical reaction rate of glyoxal. Liggio et al. (2005) reported a reactive uptake coefficient for glyoxal that varied from $8.0 \times 10^{-4}$ to $7.3 \times 10^{-3}$, and Ervens and Volkamer (2010) found that the derived first-order photochemical reaction rate for glyoxal ranges from $0.8 \mathrm{~s}^{-1}$ to $7 \mathrm{~s}^{-1}$ depending on the chemical composition of different seed aerosols. Finally, we note that we ignored the formation of aqSOA in the water associated with sea salt aerosol. The terrestrial emissions of isoprene and aromatics are much larger than those from marine sources in the IMPACT model, so the amount of glyoxal/methylglyoxal formed from the oxidation of isoprene and aromatics over oceans is smaller than that over continents. AqSOA formed in the aerosol water associated with sea salt is expected to be small as well.

A complete list of aqueous-phase reactions and their corresponding rate constants are given in Tables S1 to S8 in the Supplement. Aqueous reactions for sulfates, nitrates, $\mathrm{H}_{2} \mathrm{O}_{2}, \mathrm{O}_{3}, \mathrm{OH}$ and related radicals have been taken from Jacob (1986), Pandis and Seinfeld (1989), Lelieveld and Crutzen (1990) and Liu et al. (1997); Aqueous reactions for water-soluble organic compounds are based on recently published box modeling studies (Lim et al., 2005; Herrmann et al., 2005; Ervens and Volkamer, 2010; Lim et al., 2010); Aqueous reactions for Fe are drawn from Deguillaume et al. (2010) and the Chemical Aqueous Phase Radical Mechanism (CAPRAM) 2.4 (Ervens et al., 2003).
While the chemistry of organic species taking place in cloud droplets is relatively well established in experiments and box modeling studies, the chemistry of organic species occurring in wet particles is only now being developed so that very few models have been extended to include organic reactions (Ervens et al., 2011). Ervens and Volkamer (2010) and Lim et al. (2010) proposed different schemes for SOA formation in aerosol water. Ervens and Volkamer (2010) parameterized the SOA formation using simple first-order reaction rate constants to fit photochemical chamber experiments. Basically, gas-phase glyoxal is taken into aerosol water based on its Henry's law coefficient and is further hydrated to monohydrate and dihydrate glyoxal using explicit hydration coefficients for the hydration kinetics. The dissolved glyoxal, monohydrate and dihydrate glyoxals can react with dissolved $\mathrm{OH}$ radicals to form organic acids, or undergo oligomerization using a parameterized first-order photochemical reaction rate $k$ (unit: $\mathrm{s}^{-1}$ ). The reactions and kinetic coefficients used in this paper are listed in Table S4 in the Supplement. The reactions in Table S4 extend the Ervens and Volkamer (2010) model for glyoxal to include bulk phase reactions of methylglyoxal by adopting kinetic data from the literature.

Lim et al. (2010) describe a second aqueous SOA formation mechanism that used a set of detailed radical-radical reactions based on bulk aqueous-phase experiments. Gas-phase glyoxal is partitioned into aerosol water based on its effective Henry's law constant (implicitly accounting for its hydration) and then further reacts with dissolved $\mathrm{OH}$ radicals to form radical species by $\mathrm{H}$-atom abstraction, which combine with themselves to form dimers and trimers through so-called radical-radical reactions (Lim et al., 2010). These radicalradical reactions compete with reactions of the radicals with dissolved $\mathrm{O}_{2}$ to form organic acids. In aerosol-water relevant conditions (i.e., $1-10$ mole $^{-1}$ (M) glyoxal concentrations and $10^{-12}-10^{-11} \mathrm{M}$ dissolved $\mathrm{OH}$ radicals), over $80 \%$ of the products are oligomers. Since no kinetic data for methylglyoxal in-aerosol-water reactions were available in Lim et al. (2010), we assumed that $80 \%$ of products from the reaction of dissolved methylglyoxal with $\mathrm{OH}$ are oligomers and the rest are oxalic acid, which is consistent with the recent work of Lim et al. (2013).

\subsubsection{Surface-limited uptake process}

As an alternative to the approaches described above that use a detailed gas-phase and aqueous-phase chemical mechanism, a simpler method has also been used by Fu et al. (2008) and Lin et al. (2012) to describe the uptake of a gas and its further reaction inside particles. In this method, the loss of gasphase glyoxal or methylglyoxal on aqueous particles or cloud droplets is parameterized using the following equation:

$\frac{\mathrm{d} C_{\mathrm{g}}}{\mathrm{d} t}=-\frac{1}{4} \cdot \gamma \cdot A \cdot\left\langle v>\cdot C_{\mathrm{g}}\right.$ 
where $A$ is the total surface area of aqueous sulfate aerosols $\left[\mathrm{m}^{2} \mathrm{~m}^{-3}\right], C_{\mathrm{g}}$ is the concentration of gas-phase glyoxal or methylglyoxal, $\gamma$ is the reactive uptake coefficient, representing the probability that a molecule impacting the particle surface undergoes reaction. The value of $\gamma$ used in Fu et al. (2008) and Lin et al. (2012) was assumed to be $2.9 \times 10^{-3}$ for both glyoxal and methylglyoxal uptake on aqueous sulfate and cloud droplets. $\langle v\rangle$ is the mean molecular speed of glyoxal or methylglyoxal in the gas phase given by $(8 R T / \pi \mathrm{MW})^{-1 / 2}$ where $\mathrm{MW}$ is the molecule weight of glyoxal or methylglyoxal.

\subsection{Case set up}

As described above, there are still large uncertainties in simulating aqSOA formation in both cloud water and aerosol water. We thus set up six cases to study the sensitivity of aqSOA formation to different methods representing gasparticle mass transfer and subsequent reactions (i.e., multiphase reaction scheme vs. surface-limited uptake method), to the different chemical schemes in cloud and aerosol water reactions, to the cloud water content, and to the inclusion of $\mathrm{Fe}$ chemistry in the cloud. The descriptions of these six cases are presented here (also summarized in Table 1), and comparisons of sensitivity test simulations with Case 1 as well as with observations are shown in Sect. 3.

In Case 1, we used the detailed multiphase reaction scheme (Eq. 1a, b) to predict the production of glyoxylic acid, oxalic acid and pyruvic acid in both cloud water and aerosol water together with the kinetic uptake of glyoxal and methylglyoxal in both cloud and aerosol water described in Sect. 2.2.1. In addition, in aerosol water we used the surfacelimited uptake method (Eq. 2) to predict the formation of oligomers from glyoxal and methylglyoxal. The aqueousphase reactions of organic species used in this case are shown in Table S3 in the Supplement. Reaction rate constants were adopted from Jacob (1986), Pandis and Seinfeld (1989), Lim et al. (2005), Herrmann (2003), and Herrmann et al. (2005). For simplicity, we did not consider the effect of ionic strength of cloud water on the solubility of organics, though this is expected to increase aqSOA formation (Myriokefalitakis et al., 2011). We adopted a reactive uptake coefficient $\gamma$ of $3.3 \times 10^{-3}$ from Waxman et al. (2013) to simulate the formation of oligomers due to glyoxal in the aerosol water. The uptake coefficient of methylglyoxal was scaled to that of glyoxal by the ratio of their effective Henry's law constants (Table S7 in the Supplement). This scaling is based on the reasoning that the glyoxal and methylglyoxal uptake by aerosol water correlates with their water solubility and that glyoxal and methylglyoxal have similar chemical reactivity and undergo similar reactions in aerosol water (Lim et al., 2013). It might appear that the chemistry for Case 1 double counts the loss rate of glyoxal since it includes both a loss rate by reaction with $\mathrm{OH}$ as well as a loss rate due to a surface reaction characterized by an uptake parameter. However, the uptake parameter used in Case 1 was adopted from Waxman et al. (2013), who used a box model to test several chemical mechanisms, in order to fit the observed glyoxal concentrations in Mexico City. The best fit chemical mechanism that they found includes an uptake parameter $(\gamma)$ of $3.3 \times 10^{-3}$ as well as the reaction of $\mathrm{OH}$ with glyoxal in dilute water. Therefore we also included the uptake parameter together with the $\mathrm{OH}$ chemistry in dilute water.

In Case 2, all aqSOA formation was simulated using the multiphase reaction scheme. The chemical reactions in cloud water were the same as those used for cloud water in Case 1. The parameterized reactions proposed by Ervens and Volkamer (2010) (Table S4 in the Supplement) were used for the formation of aqSOA in aerosol water replacing the reactions from Table S3 and the uptake coefficients used in Case 1.

Case 3 also used the multiphase reaction scheme, but used the bulk reactions adopted from Lim et al. (2010) to predict the formation of aqSOA in both cloud and aerosol water. The detailed bulk phase reactions of organic species used in this case are listed in Table S5 in the Supplement. In this case, we include the further oxidation of oligomers by aqueousphase $\mathrm{OH}$ (see the reaction R38, R42, R53, and R54 in Table S5). These further reactions were not included in Case 1, because the uptake parameter represents the probability that a molecule impacting the aerosol surface will result in uptake and formation of a species which does not evaporate, and this already implicitly takes into account any chemical reactions that include the loss of oligomers inside the aerosol.

For Case 4, we employed the same chemical mechanism as in Case 1, but used the cloud field output (in-cloud liquid water content and grid-box cloud fraction) from AM3, the atmospheric component of the coupled general circulation model (CM3) developed at the NOAA Geophysical Fluid Dynamics Laboratory (GFDL) (Donner et al., 2011) in place of the NCAR CCM2 parameterization. Cloud water is a prognostic variable in the GFDL AM3 while it is diagnosed in CCM2.

In Case 5, we added Fe chemistry in cloud water (Table S6 in the Supplement) to the chemistry used in Case 1. The only source of aqueous $\mathrm{Fe}$ in the model is the dissolution of dust aerosol particles incorporated into cloud droplets. We assumed that $3.5 \%$ of the mass of dust aerosol is composed of Fe (Taylor and McLennan, 1985), only $5 \%$ of which could be dissolved into cloud water (Ito and Xu, 2014). The initial speciation of $\mathrm{Fe}(\mathrm{II}) / \mathrm{Fe}$ (III) was set to 4 (Deguillaume et al., 2010). This scheme cannot describe the spatial and time variations in dissolved $\mathrm{Fe}$ that are predicted in models that include a kinetic description of Fe dissolution (Johnson and Meskhidze, 2013; Ito and Feng, 2010) but is able to provide a first-order approximation of the dissolved Fe content in cloud water (Table S9 in the Supplement).

For Case 6, we used the surface-limited uptake process to simulate all aqSOA formation in both cloud and aerosol water, following the method of Fu et al. (2008) and Lin et al. (2012). 
Table 2. Global aqSOA budget analyses for all cases.

\begin{tabular}{|c|c|c|c|c|c|c|c|}
\hline Case name & Species name & $\begin{array}{l}\text { Chemical production } \\
\left(\operatorname{Tg~yr}^{-1}\right)\end{array}$ & $\begin{array}{c}\text { Chemical destruction } \\
\left(\operatorname{Tg~yr}^{-1}\right)\end{array}$ & $\begin{array}{l}\text { Net production } \\
\left(\operatorname{Tg~yr}^{-1}\right)\end{array}$ & $\begin{array}{l}\text { Dry deposition } \\
\left(\operatorname{Tg~yr}^{-1}\right)\end{array}$ & $\begin{array}{l}\text { Wet deposition } \\
\left(\mathrm{Tg} \mathrm{yr}^{-1}\right)\end{array}$ & $\begin{array}{l}\text { Burden } \\
(\mathrm{Tg})\end{array}$ \\
\hline \multirow{5}{*}{ Case 1} & Glyoxylic acid & 15.9 & 13.5 & 2.4 & 0.1 & 2.3 & $1.8 \times 10^{-2}$ \\
\hline & Pyruvic acid & $7.2 \times 10^{-1}$ & $5.5 \times 10^{-1}$ & $1.7 \times 10^{-1}$ & $1.0 \times 10^{-2}$ & $1.6 \times 10^{-1}$ & $1.1 \times 10^{-3}$ \\
\hline & Oxalic acid & 16.5 & 6.1 & 10.4 & 0.5 & 9.9 & $6.1 \times 10^{-2}$ \\
\hline & Glyoxal oligomer & 6.9 & - & 6.9 & 0.4 & 6.5 & $9.2 \times 10^{-2}$ \\
\hline & Methylglyoxal oligomer & $2.3 \times 10^{-1}$ & - & $2.3 \times 10^{-1}$ & $2.4 \times 10^{-2}$ & $2.0 \times 10^{-1}$ & $2.3 \times 10^{-3}$ \\
\hline \multirow{5}{*}{ Case 2} & Glyoxylic acid & 16.5 & 13.9 & 2.6 & 0.1 & 2.5 & $1.8 \times 10^{-2}$ \\
\hline & Pyruvic acid & $7.0 \times 10^{-1}$ & $5.3 \times 10^{-1}$ & $1.7 \times 10^{-1}$ & $7.8 \times 10^{-3}$ & $1.6 \times 10^{-1}$ & $1.1 \times 10^{-3}$ \\
\hline & Oxalic acid & 16.9 & 6.3 & 10.6 & 0.4 & 10.2 & $6.4 \times 10^{-2}$ \\
\hline & Glyoxal oligomer & $2.8 \times 10^{-2}$ & - & $2.8 \times 10^{-2}$ & $5.1 \times 10^{-3}$ & $2.3 \times 10^{-2}$ & $2.1 \times 10^{-3}$ \\
\hline & Methylglyoxal oligomer & $1.7 \times 10^{-2}$ & - & $1.7 \times 10^{-2}$ & $4.4 \times 10^{-3}$ & $1.3 \times 10^{-2}$ & $9.7 \times 10^{-4}$ \\
\hline \multirow{5}{*}{ Case 3} & Glyoxylic acid & 14.8 & 12.3 & 2.5 & 0.1 & 2.4 & $1.8 \times 10^{-2}$ \\
\hline & Pyruvic acid & $6.0 \times 10^{-1}$ & $4.4 \times 10^{-1}$ & $1.6 \times 10^{-1}$ & $7.8 \times 10^{-3}$ & $1.5 \times 10^{-1}$ & $1.1 \times 10^{-3}$ \\
\hline & Oxalic acid & 15.0 & 5.0 & 10.0 & 0.3 & 9.7 & $6.1 \times 10^{-2}$ \\
\hline & Glyoxal oligomer & $1.1 \times 10^{-1}$ & $7.5 \times 10^{-2}$ & $3.4 \times 10^{-2}$ & $2.6 \times 10^{-3}$ & $3.1 \times 10^{-2}$ & $2.7 \times 10^{-3}$ \\
\hline & Methylglyoxal oligomer & $1.5 \times 10^{-3}$ & - & $1.5 \times 10^{-3}$ & $8.2 \times 10^{-5}$ & $1.4 \times 10^{-3}$ & $1.2 \times 10^{-4}$ \\
\hline \multirow{5}{*}{ Case 4} & Glyoxylic acid & 8.4 & 7.4 & 1.0 & 0.1 & 0.9 & $1.4 \times 10^{-2}$ \\
\hline & Pyruvic acid & $4.5 \times 10^{-1}$ & $3.6 \times 10^{-1}$ & $9.0 \times 10^{-2}$ & $6.0 \times 10^{-3}$ & $8.0 \times 10^{-2}$ & $1.2 \times 10^{-3}$ \\
\hline & Oxalic acid & 9.0 & 4.9 & 4.1 & 0.3 & 3.8 & $5.5 \times 10^{-2}$ \\
\hline & Glyoxal oligomer & 9.7 & - & 9.7 & 0.9 & 8.8 & $1.3 \times 10^{-1}$ \\
\hline & Methylglyoxal oligomer & $4.0 \times 10^{-1}$ & - & $4.0 \times 10^{-1}$ & $5.7 \times 10^{-2}$ & $3.4 \times 10^{-1}$ & $5.0 \times 10^{-3}$ \\
\hline \multirow{5}{*}{ Case 5} & Glyoxylic acid & 23.0 & 20.6 & 2.4 & 0.1 & 2.3 & $1.5 \times 10^{-2}$ \\
\hline & Pyruvic acid & 1.8 & 1.6 & 0.2 & $1.0 \times 10^{-2}$ & $1.9 \times 10^{-1}$ & $1.3 \times 10^{-3}$ \\
\hline & Oxalic acid & 27.3 & 22.9 & 4.4 & 0.2 & 4.4 & $4.7 \times 10^{-2}$ \\
\hline & Glyoxal oligomer & 6.6 & - & 6.6 & 0.4 & 6.2 & $8.7 \times 10^{-2}$ \\
\hline & Methylglyoxal oligomer & $2.3 \times 10^{-1}$ & - & $2.3 \times 10^{-1}$ & $2.5 \times 10^{-2}$ & $2.0 \times 10^{-1}$ & $2.3 \times 10^{-3}$ \\
\hline \multirow{2}{*}{ Case 6} & Glyoxal oligomer & 22.6 & - & 22.6 & 1.0 & 21.6 & $2.0 \times 10^{-1}$ \\
\hline & Methylglyoxal oligomer & 36.9 & - & 36.9 & 1.6 & 35.3 & $3.0 \times 10^{-1}$ \\
\hline
\end{tabular}

\section{Results and discussion}

Table 2 shows the global budget of each of the aqSOA components (i.e., glyoxylic acid, pyruvic acid, oxalic acid, and oligomers) (if available) for these six cases. We note that the predicted oligomers in the model can consist of different numbers of monomers (e.g., dimers, trimers and tetramers), so that the total oligomers shown in different cases in Table 2 do not necessarily consist of identical species. We will focus on the detailed budget and global distributions of aqSOA for Case 1 in Sects. 3.1 and 3.2, and the difference between this case and other cases in Sects. 3.3-3.6.

\subsection{Global budget}

For Case 1, the net global aqSOA production rate totals 20.1 $\mathrm{Tg} \mathrm{yr}^{-1}$, over $95 \%$ of which is removed by wet deposition while the rest is removed by dry deposition. This rate is comparable to the SOA production rate of $28.0 \mathrm{Tg} \mathrm{yr}^{-1}$ formed from gas-particle partitioning and the rate of $26.0 \mathrm{Tg} \mathrm{yr}^{-1}$ formed from epoxide predicted in the model. The global annual mean aqSOA burden equals to $0.18 \mathrm{Tg}$, corresponding to a global mean life time of about 3.0 days due to deposition. Five aqSOA species are predicted: glyoxylic acid, pyru- vic acid, oxalic acid, and two classes of oligomers formed from glyoxal and methylglyoxal. Among these five aqueous SOA components, oxalic acid accounts for about $51.7 \%$ of the total aqueous SOA source, glyoxal oligomers account for about $34.3 \%$, glyoxylic acid for about $11.9 \%$, methylglyoxal oligomers for $1.1 \%$, and pyruvic acid for $1.0 \%$. While all oligomers are assumed to be formed in aerosol water, organic acids can be formed in both cloud and aerosol water. However, the contribution of aerosol water to the formation of organic acids is very small. The net production rate of glyoxylic acid in the aerosol water accounts for only $0.013 \mathrm{Tg} \mathrm{yr}^{-1}$ of the total $2.4 \mathrm{Tg} \mathrm{yr}^{-1}$ net production rate; similarly, only $2.53 \times 10^{-4} \mathrm{Tg} \mathrm{yr}^{-1}$ of the total $0.17 \mathrm{Tg} \mathrm{yr}^{-1}$ pyruvic acid is formed in aerosol water; for oxalic acid, the net production rate in the aerosol water (after consumption by reaction with $\mathrm{OH})$ is $-0.43 \mathrm{Tg} \mathrm{yr}^{-1}$, compared to the total net production rate of $10.4 \mathrm{Tg} \mathrm{yr}^{-1}$ in cloud water.

The global average reaction rates for these organic acids in cloud water for Case 1 are listed in Table 3. The glyoxylic acid production rate is $15.8 \mathrm{Tg} \mathrm{yr}^{-1}$, which is derived from the oxidation of glyoxal, glycolaldehyde, methylglyoxal and acetic acid. Glyoxal oxidation accounts for $77.2 \%$, while the oxidation of glycolaldehyde, methylglyoxal and acetic acid account for $13.9 \%, 0.7 \%$, and $8.2 \%$, respectively. Of the 
Table 3. Predicted global average production rates in cloud water by the individual reactions for Case $1^{*}$.

\begin{tabular}{llclc}
\hline & Source & $\begin{array}{c}\text { Reaction rate } \\
\left(\mathrm{Tg} \mathrm{yr}^{-1}\right)\end{array}$ & Sink & $\begin{array}{c}\text { Reaction rate } \\
\left(\mathrm{Tg} \mathrm{yr}^{-1}\right)\end{array}$ \\
\hline \multirow{5}{*}{ Glyoxylic acid } & $\begin{array}{l}\text { Glyoxal }+\mathrm{OH} / \mathrm{NO}_{3} \\
\text { Methylglyoxal }+\mathrm{OH} / \mathrm{NO}_{3}\end{array}$ & $\begin{array}{c}12.2 \\
6.5 \times 10^{-2}\end{array}$ & Reaction with $\mathrm{OH}$ & 12.7 \\
& Acetic acid $+\mathrm{OH}$ & 1.3 & Reaction with $\mathrm{NO}_{3}$ & $7.2 \times 10^{-1}$ \\
& Glycolaldehyde $+\mathrm{OH}$ & 2.2 & & 3.5 \\
\hline \multirow{2}{*}{ Oxalic acid } & Glyoxylic acid $+\mathrm{OH}$ & 14.6 & Reaction with $\mathrm{OH}$ & 1.1 \\
\hline \multirow{2}{*}{ Pyruvic acid } & Glyoxylic acid $+\mathrm{NO}_{3}$ & $8.7 \times 10^{-1}$ & Reaction with $\mathrm{NO}_{3}$ & \\
& Methylglyoxal $+\mathrm{OH}^{*}$ & $7.0 \times 10^{-1}$ & Reaction with $\mathrm{OH}_{3}$ & $5.2 \times 10^{-1}$ \\
& Methylglyoxal $+\mathrm{NO}_{3}$ & $1.5 \times 10^{-2}$ & Reaction with $\mathrm{NO}_{3}$ & $1.4 \times 10^{-3}$ \\
\hline
\end{tabular}

* Organic acids formed in cloud water account for around $67 \%$ of total aqSOA formation rate, while the rest is attributed to the oligomer formation in aerosol water.

glyoxylic acid, $85.4 \%$ is destroyed by reaction with $\mathrm{OH}$ and $\mathrm{NO}_{3}$ and the rest is deposited to the surface in wet deposition. For oxalic acid, the total cloud water production rate is equal to $15.5 \mathrm{Tg} \mathrm{yr}^{-1}$, which is similar to the estimate of $14.5 \mathrm{Tg} \mathrm{yr}^{-1}$ in Liu et al. (2012) but smaller than the estimate of $21.2 \mathrm{Tg} \mathrm{yr}^{-1}$ in Simulation S1.1 of Myriokefalitakis et al. (2011), which excluded the effect of the ionic strength of cloud water on glyoxal, glycolaldehyde and methylglyoxal, as we do here. The reaction of glyoxylic acid with $\mathrm{OH}$ is a large contributor (94\%) to the total oxalic acid production while the reaction with $\mathrm{NO}_{3}$ contributes the rest. Oxalic acid is removed from the atmosphere through its reaction with $\mathrm{OH}$ and $\mathrm{NO}_{3}$ radicals in the aqueous phase $(29.6 \%)$ and by wet and dry deposition (71.4\%). The chemical destruction rate of oxalic acid is $4.6 \mathrm{Tg} \mathrm{yr}^{-1}$. This is smaller than the estimate in Simulation S1.1 of Myriokefalitakis et al. (2011) but larger than that estimated by Liu et al. (2012). Subtracting the chemical destruction rate from the production rate, the global net production rate of oxalic acid is $10.9 \mathrm{Tg} \mathrm{yr}^{-1}$, which is slightly smaller than the value of $13.2 \mathrm{Tg} \mathrm{yr}^{-1}$ in Simulation S1.1 of Myriokefalitakis et al. (2011) and the estimate of $13.5 \mathrm{Tg} \mathrm{yr}^{-1}$ in Liu et al. (2012). The only sources of pyruvic acid are the reactions of methylglyoxal with $\mathrm{OH}$ and $\mathrm{NO}_{3}$. Over half $(72.9 \%)$ of the pyruvic acid is removed by reactions with $\mathrm{OH}$ and $\mathrm{NO}_{3}$ radicals. For glyoxal and methylglyoxal oligomers, no chemical destruction is included in the model, so these are only removed by wet and dry deposition.

The above analysis shows the importance of glyoxal, glycolaldehyde, methylglyoxal and acetic acid as precursors leading to aqueous SOA formation. The global budgets of these four species for Case 1 are summarized in Table 4 . While all of the glyoxal, glycolaldehyde and methylglyoxal is generated by the oxidation of VOCs in the gas and aqueous phase, around half of the acetic acid is directly emitted into the atmosphere through biomass burning. The global glyoxal production in the gas phase is equal to $69.6 \mathrm{Tg} \mathrm{yr}^{-1}$, while reactions in cloud water contribute $3.4 \mathrm{Tg} \mathrm{yr}^{-1}$ from the oxidation of dissolved glycolaldehyde. About $68.5 \%$ of the total glyoxal is consumed in the gas phase, while $24.4 \%$ is oxidized in cloud water and taken up by aqueous aerosol. The rest is deposited to the surface. The total source of methylglyoxal is $167.3 \mathrm{Tg} \mathrm{yr}^{-1}$. Of this only $0.88 \mathrm{Tg} \mathrm{yr}^{-1}$ is absorbed and oxidized in cloud water and in aqueous aerosol. Most of the methylglyoxal is destroyed in the gas phase or deposited to the surface. The net chemical production of glycolaldehyde in the gas phase is about $17.8 \mathrm{Tg} \mathrm{yr}^{-1}$, of which $29.8 \%$ is dissolved in cloud water and reacts with $\mathrm{OH}$ and $\mathrm{NO}_{3}$. For acetic acid, the uptake rate by clouds is $0.82 \mathrm{Tg} \mathrm{yr}^{-1}$, which can be compared to its total source strength of $60.9 \mathrm{Tg} \mathrm{yr}^{-1}$. The uptake rate of acetic acid is smaller than the estimate of $6.96 \mathrm{Tg} \mathrm{yr}^{-1}$ by Liu et al. (2012). This is because of the smaller total atmospheric source strength of acetic acid $\left(60.9 \mathrm{Tg} \mathrm{yr}^{-1}\right.$ vs. $78 \mathrm{Tg} \mathrm{yr}^{-1}$ ), the larger portion of gas-phase consumption of acetic acid (43\% vs. $32 \%)$, and the smaller Henry's law constant $\left(3500 \mathrm{~mol} \mathrm{~L}^{-1} \mathrm{~atm}^{-1}\right.$ vs. $\left.8800 \mathrm{~mol} \mathrm{~L}^{-1} \mathrm{~atm}^{-1}\right)$ in our model compared to those in Liu et al. (2012). Aqueous aerosol contributes a negligible amount to the sinks of both glycolaldehyde and acetic acid.

\subsection{Global distribution and seasonal variability}

Figure 1 presents the global annual mean surface mass concentrations (at approximately $970 \mathrm{hPa}$ ) of total aqSOA, total organic acids (i.e., glyoxylic acid, pyruvic acid, and oxalic acid) which are formed mainly in cloud water, and oligomers formed in aqueous aerosol. The zonal mean vertical distributions are also shown. The total aqSOA concentrations show large values over tropical Africa, the Amazon Basin, eastern Asia, the eastern United States and Europe. The SOA distributions are determined by their precursor (mainly glyoxal) distributions, oxidant (which is primarily dissolved $\mathrm{OH}$ radicals) distributions, and the availability of cloud water or aerosol water. The maximum SOA concentrations over tropical Africa and the Amazon Basin reflect the large biogenic VOC emissions and the resulting glyoxal concentration to a 
Table 4. Global budgets of aqSOA precursors $\left(\mathrm{Tg} \mathrm{yr}^{-1}\right)$ for Case 1 .

\begin{tabular}{lrrrr}
\hline & Glyoxal & Methylglyoxal & Glycolaldehyde & Acetic Acid \\
\hline Emission & 0 & 0 & 0 & 31.4 \\
Gas-phase production & 69.6 & 167.3 & 81.5 & 29.5 \\
Aqueous-phase production & 3.4 & 0 & 0 & $3.8 \times 10^{-1}$ \\
Gas-phase consumption & 47.7 & 158.0 & 63.7 & 25.9 \\
Aqueous-phase consumption & 17.0 & 0.88 & 5.3 & 1.2 \\
Deposition & 8.3 & 9.3 & 12.5 & 34.2 \\
\hline
\end{tabular}

great extent. The different patterns shown for organic acid concentrations (Fig. 1c) and for methylglyoxal and glyoxal derived oligomer concentrations (Fig. 1e) are due to the different patterns of cloud and aerosol water content (Fig. 2). Aerosol water content is due to sulfate, which peaks over the industrial regions in the Northern Hemisphere because the largest source of sulfate is from anthropogenic emissions. In contrast, most of the cloud water is located over the tropics and the Southern Hemisphere. This contrast is also reflected in the vertical zonal mean distributions of organic acids and oligomers (Fig. 1d and f). There is a hot spot in organic acids over the tropics, most of which are formed in cloud water, while the peak is located over the Northern Hemisphere for the oligomers, all of which are formed in aqueous aerosols.

The column burdens of organic acids and oligomers in winter (December, January, and February) and in summer (June, July, and August) are presented in Fig. 3. During the winter, the column burden of organic acids peaks over tropical land areas because of the huge biogenic emissions in these regions. During the summer, a secondary column burden maximum arises over the Northern Hemisphere land areas, which can be attributed to the enhanced photochemistry and biogenic emissions over these regions in the summer. The combination of enhanced photochemistry and larger biogenic emissions can increase the production of aqSOA precursors (e.g., glyoxal) and aqueous $\mathrm{OH}$ radicals, the latter due to increased photolysis of $\mathrm{H}_{2} \mathrm{O}_{2}$ in cloud water. For the same reason, the column burden of oligomers in the summer shows larger values that are spread over a wider area than those in the winter over the Northern Hemisphere (see the right panels in Fig. 3).

\subsection{Surface-limited uptake method vs. multiphase reaction scheme}

As shown in Table 2, the production rates of oligomers in Case 1 are higher than those in Case 2, which suggests that the value of the reactive uptake coefficient $\gamma$ adopted from Waxman et al. (2013) is higher than that implied by the simulation with the Ervens and Volkamer (2010) aqueous-phase aerosol chemical mechanism. Indeed, we can derive a global averaged $\gamma$ from Eq. (2) for the uptake of glyoxal or methylglyoxal into aqueous aerosol from Case 2. We integrated the left side and the right side of Eq. (2) globally and annually, and thus obtained a global averaged annual mean reactive uptake probability from the following equation:

$\bar{\gamma}=\left(\sum \frac{\mathrm{d} C_{\mathrm{g}}}{\mathrm{d} t}\right) /\left(\sum-\frac{1}{4} \cdot A \cdot\left\langle v>\cdot C_{\mathrm{g}}\right)\right.$.

The derived global averaged $\bar{\gamma}$ for the uptake of glyoxal into aqueous aerosol is $1.41 \times 10^{-5}$, while the $\bar{\gamma}$ for the uptake of methylglyoxal into aqueous aerosol is $1.47 \times 10^{-5}$. This value for glyoxal uptake is much smaller than the value of $3.30 \times 10^{-3}$ suggested by Waxman et al. (2013) or the value of $2.90 \times 10^{-3}$ derived by Liggio et al. (2005). The value derived here for methylglyoxal uptake is comparable to the value of $2.92 \times 10^{-5}$ that we used for methylglyoxal uptake in Case 1. The reason for the discrepancy between measurement studies (i.e., Waxman et al., 2013 and Liggio et al., 2005) and the values derived here might be that the actual value of the uptake parameter in remote and rural regions is smaller than that derived in urban regions (i.e., Mexico City in the case of Waxman et al., 2013) or/and that the bulk phase reactions adopted from Ervens and Volkamer (2010) may not include the full set of reactions of glyoxal that the uptake parameter method accounts for. In particular, the smaller uptake parameter in rural regions than in urban regions might be due to weaker particle acidity and lower dissolved organic compound concentration in rural regions. The glyoxal uptake rate is observed to be higher in more acidic particles (Liggio et al., 2005). The more concentrated organic compounds in aerosol water might lead to a higher oligomer formation rate (Tan et al., 2009). Also, the bulk phase reactions do not include any surface reactions of glyoxal that the uptake parameter method would include. We note that the derived uptake parameter of the order of $1 \times 10^{-5}$ is a globally averaged uptake parameter. Of course, the spatial aqSOA burden which would be predicted using this global average uptake parameter would be different than that predicted using the explicit aqueous formation mechanism. While deriving $\gamma$ in lab studies is useful, this method for determining $\gamma$ assumes that all of the gas incorporated into the aqueous phase stays in this phase. The explicit chemistry scheme is more demanding of computer time than the use of a single $\gamma$, but it is able to capture the dynamic evolution of aqSOA formation. 

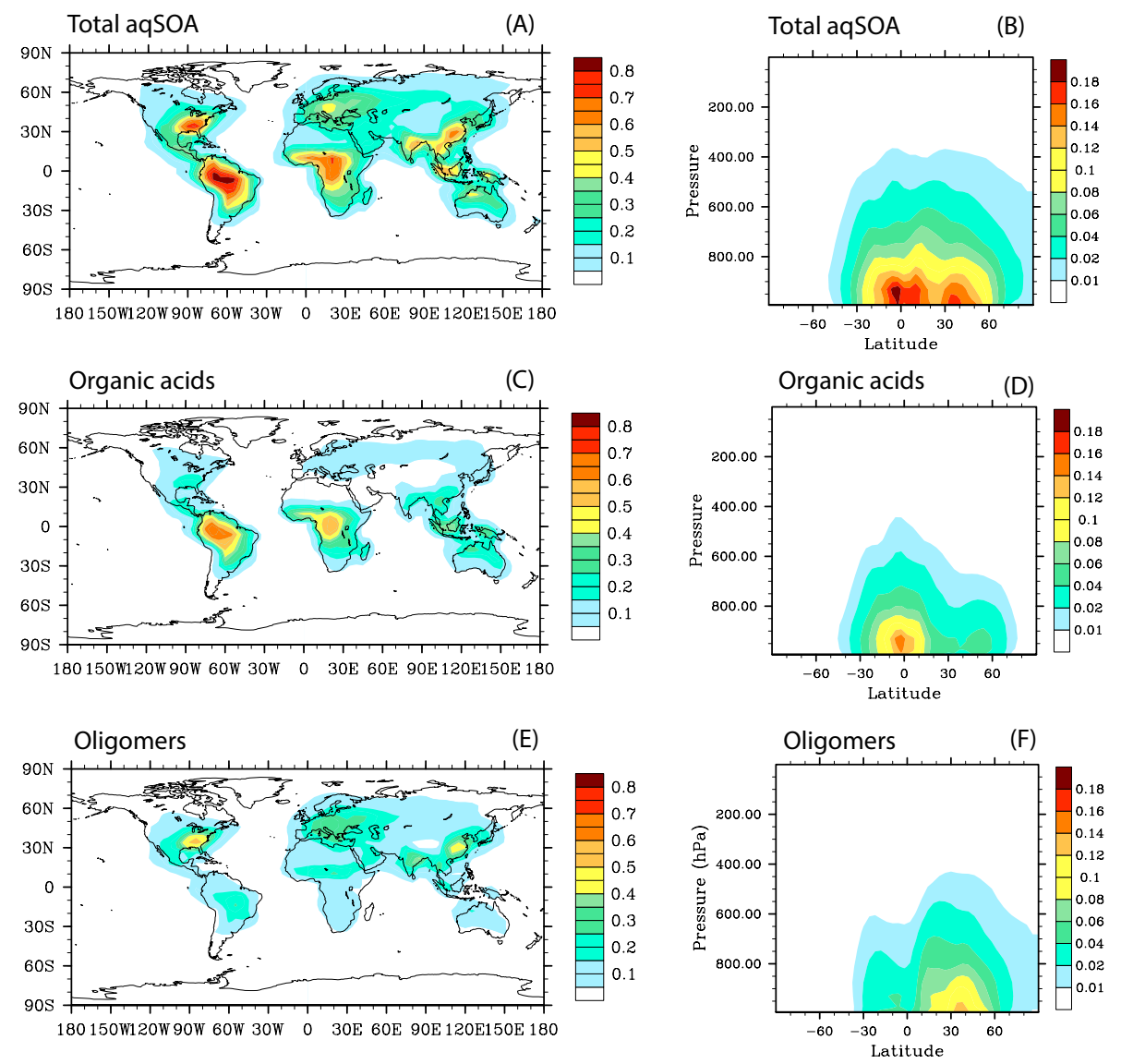

Figure 1. Annual mean simulated concentrations of total aqSOA (A, B), organic acids (the sum of glyoxylic acid, pyruvic acid, and oxalic acid) (C, D), and oligomers from glyoxal and methylglyoxal (E, F). The left column shows the global distributions at the level of $971 \mathrm{hPa}$ in the model; the right column depicts the zonal mean distributions. All plots are for Case 1 . Units: $\mu \mathrm{g} \mathrm{m}^{-3}$.

\subsection{The effect of cloud water content}

The global near-surface distribution of grid-box averaged cloud water content for Case 4 is shown in Fig. 4a while Fig. $4 \mathrm{~b}$ shows the zonal annual mean distribution. The cloud water content in Case 1 (Fig. 2) is higher than that in Case 4 almost everywhere below about $900 \mathrm{hPa}$, leading to larger global organic acids sources and burdens (Table 2). The averaged cloud water content and the net SOA production rate in cloud water below about $900 \mathrm{hPa}$ in Case 1 is 2.7 times and 4 times higher than those in Case 4, respectively. Figure $4 \mathrm{c}$ shows the ratio of cloud water content in Case 1 to that in Case 4 while Fig. $4 d$ shows the ratio of the aqSOA production rate in cloud water. Both the pattern and value of these ratios are generally similar below about $900 \mathrm{hPa}$, but above $900 \mathrm{hPa}$ neither the pattern nor the value is similar. $\mathrm{He}$ et al. (2013) studied the relationship between the aqueous SOA formation and cloud water content and proposed a parameterization in which its formation rate is linear in the cloud water content and correlates nonlinearly (concavely) with the total glyoxal and methylglyoxal precursor carbon chemical loss. At lower altitudes where the cloud water con- centration in Case 1 is more than a factor of 4 larger than that in Case 4, the linear effect of the change in cloud water content would be expected to dominate the change in the aqSOA production rate. At higher altitudes (approximately between $900 \mathrm{hPa}$ and $200 \mathrm{hPa}$ ) where the ratio of cloud water content between in Case 1 and in Case 4 is less than 4, the effect of the change in precursor concentrations (mainly due to the change of wet deposition rates as we show below) may dominate the change in the aqSOA production rate.

The lifetime of oxalic acid with respect to deposition in Case 4 is longer than that in Case 1 (4.9 days in Case 4 vs. 2.1 days in Case 1), because in Case 4 more oxalic acid is produced at high altitudes or high latitudes and less (by a factor of over 10) is formed at low altitudes in tropical regions (Fig. 4d). Oxalic acid can be precipitated out more easily in the tropics than in other regions because precipitation amounts are larger, especially that due to convective precipitation. For similar reasons, we predict a longer lifetime of sulfate aerosol in Case 4 than that in Case 1. In addition, a slightly larger aqueous-phase production rate of sulfate aerosol $\left(93.3 \mathrm{Tg} \mathrm{yr}^{-1}\right)$ is also found in Case $4 \mathrm{com}-$ pared to that in Case $1\left(91.6 \mathrm{Tg} \mathrm{yr}^{-1}\right)$. This results from the 

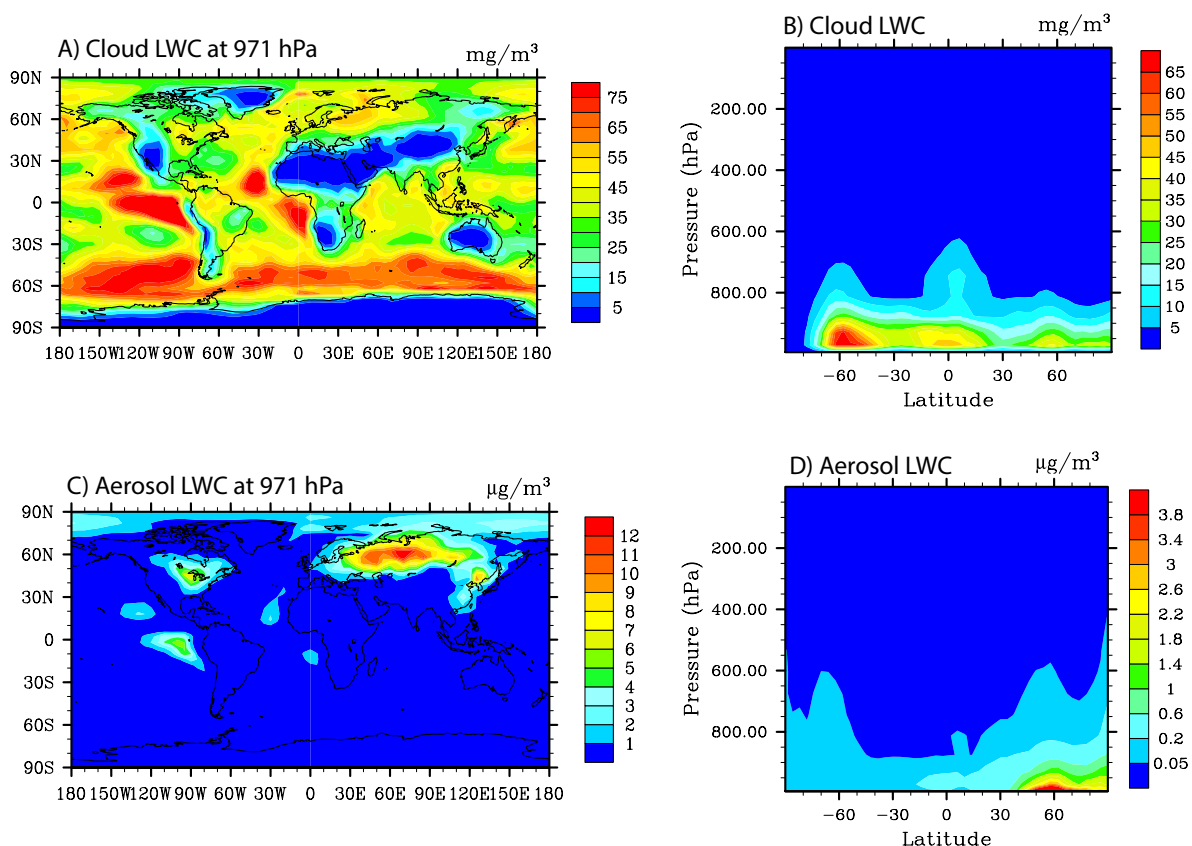

Figure 2. Annual mean grid-box averaged cloud liquid water content (LWC) in $\mathrm{mg} \mathrm{m}^{-3}$ at approximately $971 \mathrm{hPa}$ (A) and zonal mean content (B), and annual mean aerosol LWC in $\mu \mathrm{g} \mathrm{m} \mathrm{m}^{-3}$ at approximately $971 \mathrm{hPa}(\mathbf{C})$ and zonal mean content (D). Plots are for Case 1 , but are the same for all cases except Case 4 (compare Fig. 4).
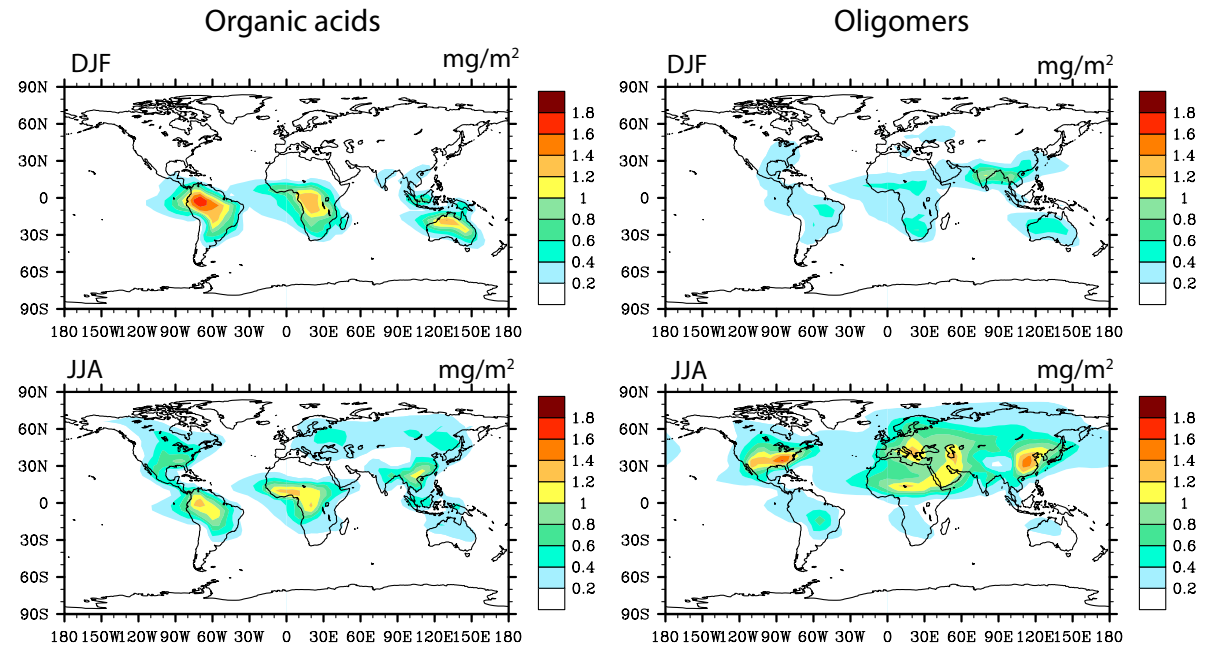

Figure 3. Seasonally averaged column concentrations $\left(\mathrm{mg} \mathrm{m}^{-2}\right)$ of organic acids (left column) and oligomers (right column) in December, January, and February (DJF) (top row) and in June, July and August (JJA) (bottom row). All plots are for Case 1.

more abundant cloud water in Case 4 in the Northern Hemisphere, where most of sulfate is formed. The longer lifetime and larger aqueous production rate of sulfate causes a larger sulfate burden and thus a larger oligomer formation rate in sulfate aerosol water.

\subsection{The effect of Fe chemistry in cloud water}

Inclusion of Fe chemistry in cloud water decreases the global average net production of oxalate by $57.6 \%$, although it in- creases both the chemical production and destruction of carboxylic acids in cloud water (Table 2). The increase of the chemical production rate is due to the increase of the aqueous $\mathrm{OH}$ radical source. Figure 5 depicts the global distribution of annual mean aqueous $\mathrm{OH}$ radical concentrations near $971 \mathrm{hPa}$ for Case 1 and Case 5. The largest increase of aqueous $\mathrm{OH}$ radicals due to the inclusion of $\mathrm{Fe}$ chemistry occurs over regions where there are abundant dust aerosols. Arakaki et al. (2013) estimated the steady-state concentrations of $\mathrm{OH}$ 

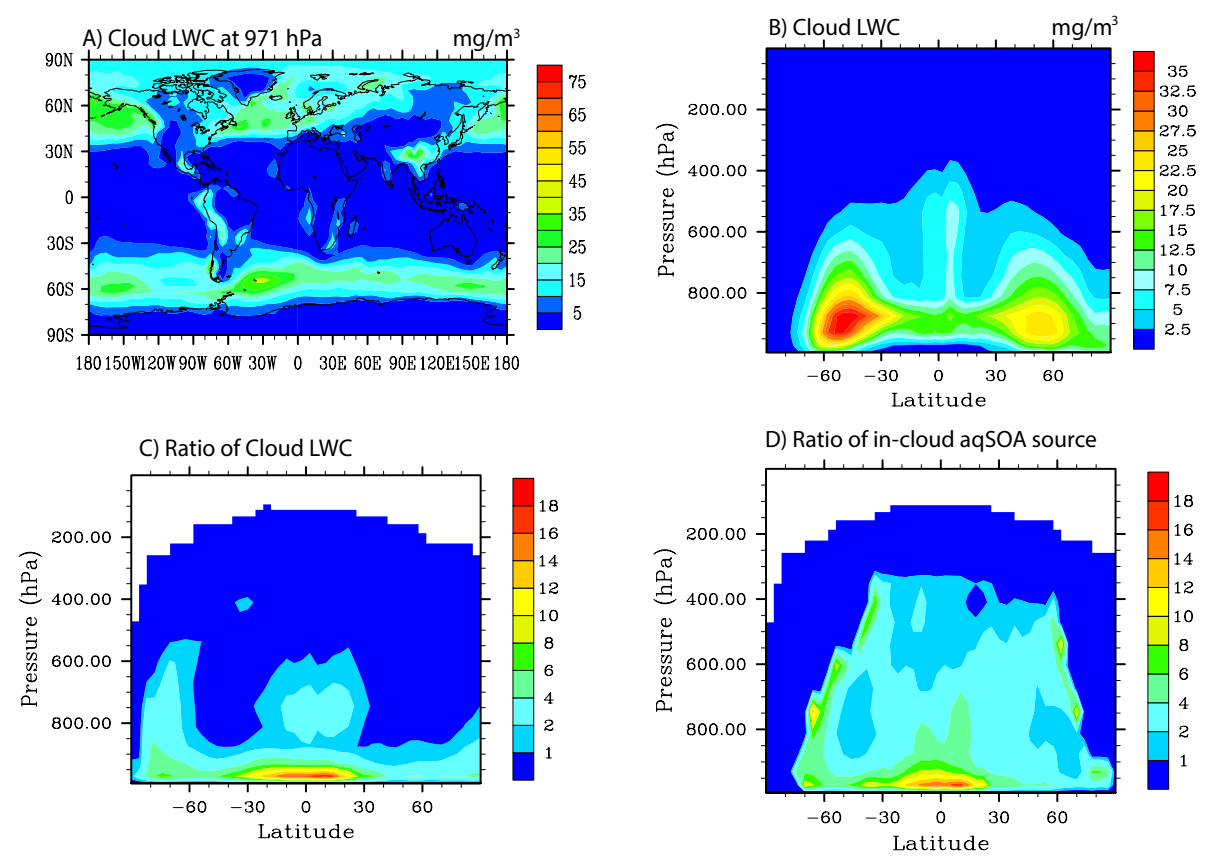

Figure 4. Annual mean grid-box averaged cloud liquid water content (LWC) in $\mathrm{mg} \mathrm{m}^{-3}$ from the GFDL AM3 cloud field at approximately $971 \mathrm{hPa}(\mathbf{A})$ and zonal mean content (B) for Case 4. The zonal mean distributions for the ratio of grid-box averaged cloud LWC in Case 1 to that in Case 4 is shown in (C); the zonal mean distributions for the ratio of the source of aqSOA formed in cloud water in Case 1 to that in Case 4. is shown in (D)

in cloud water sampled over remote North American continental regions. The estimated average $\mathrm{OH}$ concentration is $7.2 \times 10^{-15} \mathrm{~mol} \mathrm{~L}^{-1}$. The predicted average $\mathrm{OH}$ concentration in this region is $9.0 \times 10^{-14} \mathrm{~mol} \mathrm{~L}^{-1}$ in Case 5 and $8.8 \times 10^{-14} \mathrm{~mol} \mathrm{~L}^{-1}$ in Case 1 . Thus the modeled $\mathrm{OH}$ concentrations in cloud water for both cases are higher than those estimated by Arakaki et at. (2013). Arakaki et al. (2013) also estimated that the averaged total $\mathrm{OH}$ production rate in cloud water is $1.9 \times 10^{-9} \mathrm{~mol} \mathrm{~L}^{-1} \mathrm{~s}^{-1}$ and $\mathrm{OH}$ loss rate constant is $2.6 \times 10^{5} \mathrm{~s}^{-1}$. In the model, the averaged total $\mathrm{OH}$ production rate in this region is $1.06 \times 10^{-8} \mathrm{~mol} \mathrm{~L}^{-1} \mathrm{~s}^{-1}$ in Case 5 and $1.03 \times 10^{-8} \mathrm{~mol} \mathrm{~L}^{-1} \mathrm{~s}^{-1}$ in Case 1. The $\mathrm{OH}$ loss rate is $1.18 \times 10^{5} \mathrm{~s}^{-1}$ in Case 5 and $1.17 \times 10^{5} \mathrm{~s}^{-1}$ in Case 1. This comparison suggests that an overestimation of $\mathrm{OH}$ sources is the major reason for the higher $\mathrm{OH}$ concentration in the model. Arakaki et al. (2013) attributed the higher $\mathrm{OH}$ concentration in cloud water predicted in most box models to their underestimation of $\mathrm{OH}$ loss rates. This is not the case in our model. Our OH loss rate of about $1.2 \times 10^{5} \mathrm{~s}^{-1}$ compares to values obtained in those box models that range from $2.0 \times 10^{4} \mathrm{~s}^{-1}$ to $7.7 \times 10^{4} \mathrm{~s}^{-1}$ (Table S2 in Arakaki et al., 2013).

The global aqueous $\mathrm{OH}$ radical source in the troposphere (below approximately $200 \mathrm{hPa}$ ) in Case 5 is 2.6 times larger than that in Case 1 because of the formation of $\mathrm{OH}$ radicals through the reaction of $\mathrm{Fe}(\mathrm{II})$ with $\mathrm{H}_{2} \mathrm{O}_{2}$ and the photolysis of $\mathrm{Fe}$ (III) oxalate complexes. The largest increase occurs over the Sahara desert, northwestern China and Mongolia where there are large amounts of dust aerosol (Fig. 5). The enhancement of aqueous $\mathrm{OH}$ radicals leads to an increase of $10.8 \mathrm{Tg} \mathrm{yr}^{-1}$ in the oxalate chemical production rate and partly accounts for an increase of $16.8 \mathrm{Tg} \mathrm{yr}^{-1}$ in the oxalate chemical destruction rate. Another reason for the increase in the oxalate chemical destruction rate is the fast photolysis of the Fe oxalate complex $\left[\mathrm{Fe}\left(\mathrm{C}_{2} \mathrm{O}_{4}\right)_{2}\right]^{-}$, which transforms $\mathrm{C}_{2} \mathrm{O}_{4}^{2-}$ to $\mathrm{CO}_{2}$. The larger increase in the chemical destruction rate compared to the chemical production rate results in a decrease in the net chemical production rate $\left(6.0 \mathrm{Tg} \mathrm{yr}^{-1}\right)$ of oxalate, and thus a decrease in the burden as well. $\mathrm{Fe}$ oxalate complex photolysis accounts for $21.7 \mathrm{Tg} \mathrm{yr}^{-1}$ of oxalate destruction, while the destruction rate through $\mathrm{OH}$ and $\mathrm{NO}_{3}$ reactions is $1.20 \mathrm{Tg} \mathrm{yr}^{-1}$. This significant sink of oxalate by Fe-complex photolysis is consistent with the finding by Sorooshian et al. (2013) who observed that oxalate concentrations are negatively correlated with observed Fe concentrations. Sorooshian et al. (2013) used a box model to simulate oxalate formation with and without Fe chemistry. They found that the oxalate concentration would decrease when increasing the dissolved Fe concentration, but gradually levels off at $15 \%$ of the concentration predicted without consideration of $\mathrm{Fe}$ chemistry. Our model results show that the oxalate concentration with Fe chemistry is about $44 \%$ of that predicted without Fe. The inclusion of Fe chemistry decreases the formation rate of glyoxal oligomers from 6.9 $\mathrm{Tg} \mathrm{yr}^{-1}$ in Case 1 to $6.6 \mathrm{Tg} \mathrm{yr}^{-1}$ in Case 5, which is due to the increased absorption rate of glyoxal in cloud water and 

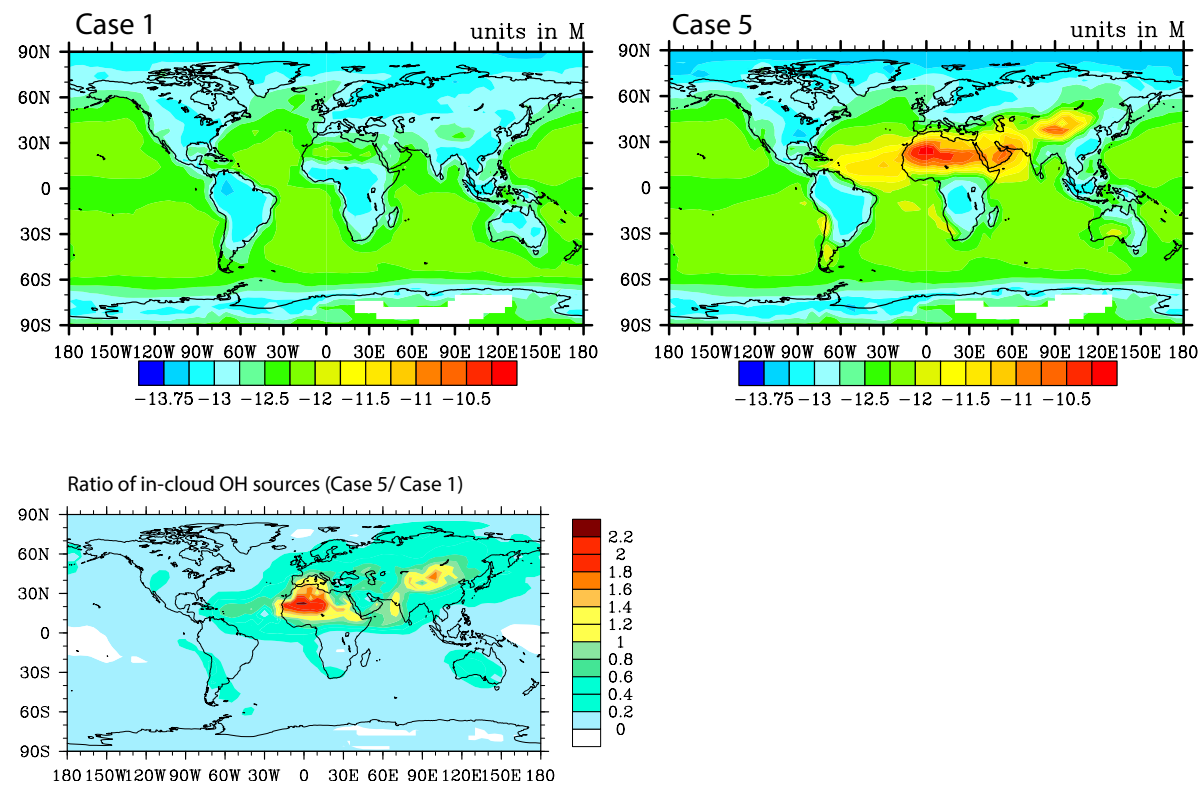

Figure 5. The predicted aqueous $\mathrm{OH}$ concentration (units in $\mathrm{mol} \mathrm{L}^{-1}$ ) in cloud water near $971 \mathrm{hPa}$ in Case 1 (without Fe chemistry) and Case 5 (with Fe chemistry). The ratio of annual mean cloud water $\mathrm{OH}$ radical production rates in Case 5 to that in Case 1 is also shown (2nd row). The value shown is the logarithm of the ratio.

thus less glyoxal uptake in aqueous aerosol. The absorption rate of glyoxal in cloud water is increased because the increased $\mathrm{OH}$ radicals in cloud water cause more glyoxal to be consumed so that more gas-phase glyoxal can be taken up by clouds.

\subsection{SOA formation in clouds vs. SOA formation in aerosol water}

On a global average basis, the fraction of SOA formed in cloud water varies from case to case, ranging from $44.4 \%$ in Case 4 to $103.2 \%$ in Case 3 (Table 5). SOA formed in cloud water accounts for about $70 \%$ and $80 \%$ of total aqSOA in Case 1 and Case 6, respectively; the net SOA production rate in aerosol water is less than zero in Case 2 and Case 3, which means that aqSOA is consumed in aerosol water. This is because the oxalic acid formed in cloud water subsequently dissolves into the aerosol water after cloud water evaporates and then further reacts with the high concentration of dissolved $\mathrm{OH}$ radicals inside the aerosol water, as shown in Sect. 3.1. The rate of destruction of oxalic acid by reaction with $\mathrm{OH}$ is larger than that of the rate of production from the reaction of glyoxylic acid with $\mathrm{OH}$. Nevertheless, oligomers can still form in the aerosol water, with a production rate of $4.5 \times 10^{-2} \mathrm{Tg} \mathrm{yr}^{-1}$ and $3.6 \times 10^{-2} \mathrm{Tg} \mathrm{yr}^{-1}$ for Case 2 and Case 3, respectively. The amount of oligomers formed in aerosol water is similar for Case 2 and Case 3, consistent with the finding by Ervens et al. (2011), who showed that their parameterized reaction system produces a similar amount of SOA as that of Lim et al. (2010) in box model simulations. The relative importance of SOA formed in cloud water decreases to $44.4 \%$ in Case 4 when using the GFDL AM3 cloud field because of the decrease in the cloud water content in the tropics together with the increased cloud water content in the Northern Hemisphere. In Case 5, which includes Fe chemistry in cloud water, the SOA production rate in cloud water explains $52.9 \%$ of total aqSOA production rate (see the Sect. 3.5. for details).

\subsection{Discussion of uncertainties}

While we have discussed a number of uncertainties concerning the production of aqSOA, there are additional uncertainties that need to be explored. Liu et al. (2012) used a global model to study the sensitivity of their predicted aqSOA incloud to cloud lifetime, cloud droplet size and cloud fraction. They found that the predicted aqSOA was sensitive to the cloud lifetime and cloud fraction while it depended only weakly on the cloud droplet size. Waxman et al. (2013) studied the sensitivity of aqSOA formation in aerosol to aerosol size distributions. Little size dependence was reported for the case using the multiphase reaction scheme, but the uptake method showed a strong sensitivity to size distribution because of changes in the surface to volume ratio.

Furukawa and Takahashi (2011) used X-ray absorption fine structure spectroscopy (XAFS) to show that most of the oxalate within aerosol particles is present as metal-oxalate complexes, especially as $\mathrm{Ca}$ and $\mathrm{Zn}$ oxalate complexes. Xing et al. (2013) also suggest the formation of a stable $\mathrm{Zn}$ oxalate complex in the aerosol phase in urban aerosols over China. These complexes are weakly water soluble and very stable, which prevents oxalate from being oxidized by $\mathrm{OH}$ in aerosol 
Table 5. aqSOA formation in cloud water vs. aqSOA formation in aerosol water.

\begin{tabular}{rrrrr}
\hline & $\begin{array}{r}\text { SOA production } \\
\text { rate in cloud water } \\
\left(\mathrm{Tg} \mathrm{yr}^{-1}\right)\end{array}$ & $\begin{array}{r}\text { SOA production } \\
\text { rate in aerosol } \\
\text { water }\left(\mathrm{Tg} \mathrm{yr}^{-1}\right)\end{array}$ & $\begin{array}{r}\text { Total aqSOA } \\
\text { production rate } \\
\left(\mathrm{Tg} \mathrm{yr}^{-1}\right)\end{array}$ & $\begin{array}{r}\text { Fraction of SOA } \\
\text { production } \\
\text { in cloud water }\end{array}$ \\
\hline Case 1 & 13.4 & 6.7 & 20.1 & $66.7 \%$ \\
Case 2 & 13.8 & -0.4 & 13.4 & $103.0 \%$ \\
Case 3 & 13.1 & -0.4 & 12.7 & $103.2 \%$ \\
Case 4 & 6.8 & 8.5 & 15.3 & $44.4 \%$ \\
Case 5 & 7.3 & 6.5 & 13.8 & $52.9 \%$ \\
Case 6 & 46.8 & 12.6 & 59.4 & $78.8 \%$ \\
\hline
\end{tabular}

water. We did not include these effects in our model due to the lack of detailed information, but it is clear that their inclusion could increase the amount of oxalate in aerosol water.

Many studies have suggested a 2-3 order of magnitude enhancement in the effective Henry's law constant for glyoxal for aerosol conditions compared to cloud conditions (Kroll et al., 2005; Volkamer et al., 2009; Kampf et al., 2013). To test the potential effect of this enhancement, we added a sensitivity test based on Case 3 but increased the effective Henry's law constants of glyoxal and methylglyoxal for aerosol water by 3 orders of magnitude. In this sensitivity case, the chemical production rate of glyoxal oligomer is $4.65 \times 10^{-1} \mathrm{Tg} \mathrm{yr}^{-1}$, and the chemical destruction rate is $1.95 \times 10^{-1} \mathrm{Tg} \mathrm{yr}^{-1}$, leading to a net production rate that is roughly a factor of 10 larger than that in Case 3, $1.95 \times 10^{-1} \mathrm{Tg} \mathrm{yr}^{-1}$. The net production rate for methylglyoxal oligomer is increased by more than a factor of 10 , to $8.68 \times 10^{-2} \mathrm{Tg} \mathrm{yr}^{-1}$. These increases in net production rates lead to an increase in oligomer burden by a factor of 4.4. However, these enhanced net production rates and global burdens are still smaller than those predicted in the Case 1 which adds the Waxman et al. (2013) uptake method for the production of aqSOA in aqueous aerosol.

The formation and loss of oxalate by aqueous-phase $\mathrm{OH}$ depends strongly on the $\mathrm{pH}$ value (see Reactions (R2)-(R6) in Table S3), because the rate constants for the oxidation of glyoxylic acid and oxalic acid are smaller than those of their anions (i.e., glyoxylate and oxalate) and the relative abundance of these acids and their anions depends on $\mathrm{pH}$ values. We present the predicted annual mean cloud water $\mathrm{pH}$ near $971 \mathrm{hPa}$ in Fig. S1 in the Supplement and compare our predicted $\mathrm{pH}$ values with observations from the literature (Table S10 in the Supplement). The results agree with observations at some locations, but show that the model is too acidic in other locations. We would expect the oxalate concentrations to vary little if $\mathrm{pH}$ values were increased, because both the formation rate and the destruction rate of oxalate would increase. This weak dependence of aqSOA formed in cloud water has been observed in a parcel model that included a multiphase reaction mechanism similar to that which we use in this work (Ervens et al., 2008).
The comparison of Case 2 and Case 3 with Case 1 shows that the use of only the multiphase reaction scheme for aerosol water decreases the global total aqSOA burden by around $50 \%$. In the case which increases the effective Henry's law constant by 3 orders of magnitude, the aqSOA burden remains lower than that predicted in Case 1 by $42 \%$. The replacement of the diagnostic cloud field with the GFDL AM3 cloud field causes the burden to increase by $16 \%$. In the case which includes Fe chemistry in cloud water, the burden is predicted to be smaller than that in Case 1 by $11 \%$. The use of the uptake parameter method for both cloud water and aerosol water in Case 6 predicts a burden $185 \%$ larger than Case 1.

\section{Comparison with measurements}

In this section, we compare model results to measured oxalate, aerosol mass spectrometer (AMS) measurements of $\mathrm{SOA}$, and SOA O/C ratios. Oxalate is a major component of aqSOA formed in cloud water, and thus the comparison of oxalate with observations gives us a direct evaluation of the modeled aqSOA, while comparison of SOA measured by AMS data and $\mathrm{O} / \mathrm{C}$ ratios can indirectly constrain the modeled aqSOA.

\subsection{Oxalate}

Figure 6 compares the modeled oxalic acid near $971 \mathrm{hPa}$ with the measured oxalate compiled in Table S3 of Myriokefalitakis et al. (2011). We only show this comparison for Case 1, Case 4, and Case 5, since the oxalic acid concentrations in the other cases are similar to those in Case 1 (Table 2). Although oxalate measurements are sparse around the world, the observations listed here cover values over most continents: United States, Europe, China, Amazon Basin and Africa. These measurements have time sampling durations which span several days up to 2 years. For this comparison, the monthly simulation data were sampled for the specific month and at the specific location corresponding to the measurements. It should be noted that due to the coarse resolution used in the model $\left(4^{\circ}\right.$ by $\left.5^{\circ}\right)$, we do not expect the 
model to be able to predict the high concentrations seen in urban regions and hence we leave these out. Over rural areas, the model performance varies in different regions and different seasons. In Europe, the results for Case 1 underestimate almost all observations, although the results for summer are relatively better (green triangles in Fig. 6) than those in winter (black dots in Fig. 6). The difference in the model performance between summer and winter may be attributed to different oxalate sources in these two seasons. According to Legrand et al. (2007), the major oxalate sources at the CARBOSOL (the Project of Carbonaceous Aerosols over Europe) surface stations in winter are fast secondary production in wood burning plumes and secondary production through the rapid oxidation of toluene and ethane emitted from vehicles. In summer these anthropogenic emissions decrease and biogenic emissions (e.g., isoprene) increase and make an important contribution to the oxalate source via multiphase photochemical reactions. These four CARBOSOL sites are included in the comparison here and we suspect the other European sites that we included have similar oxalate sources to those at the CARBOSOL sites. Unlike what is expected for the measurements, the model can not represent the rapid secondary formation of oxalic acid from local sources. Other factors which might also contribute to the model underestimation include a low cloud water content or high deposition rates in the model. When using the GFDL AM3 cloud field, the model prediction improves at some sites.

As shown by the red squares in Fig. 6, the model also significantly underestimates the measured oxalate concentrations at two of the three sites in the Amazon Basin. One possible reason for this underestimation is that the model does not include the oxalate source from biomass burning either through direct emission or through secondary formation from carbohydrate species in smoke aerosols (e.g., levoglucosan) during aerosol aging (Gao et al., 2003). At these two sites, biomass burning is the major source of oxalate formation (Falkovich et al., 2005; Kundu et al., 2010; Graham et al., 2002). At the site where the aerosol samples were believed to be out of the influence of biomass burning (Talbot et al., 1988), the modeled oxalate concentration in Case 1 is higher than the observation, but in Case 4 (using the GFDL AM3 cloud field) the model still underestimates the observation.

There are only two sites in China and three sites in US with oxalate measurements for comparison to the model. The model underestimates the observations in China, especially at the Mangshan site, $40 \mathrm{~km}$ north of Beijing, polluted by air mass transported from Beijing (He and Kawamura, 2010). This site has a high oxalate concentration of $760 \mathrm{ng} \mathrm{m}^{-3}$. The model cannot represent the local emissions and thus only captures less than $10 \%$ of the observation. Using the GFDL AM3 cloud field does not improve the model performance. Overestimation of oxalate deposition in the model may also contribute to this underprediction. The three blue circles in Fig. 6 show the comparisons for the sites in United States, and indicate that the model does reasonably well, except for
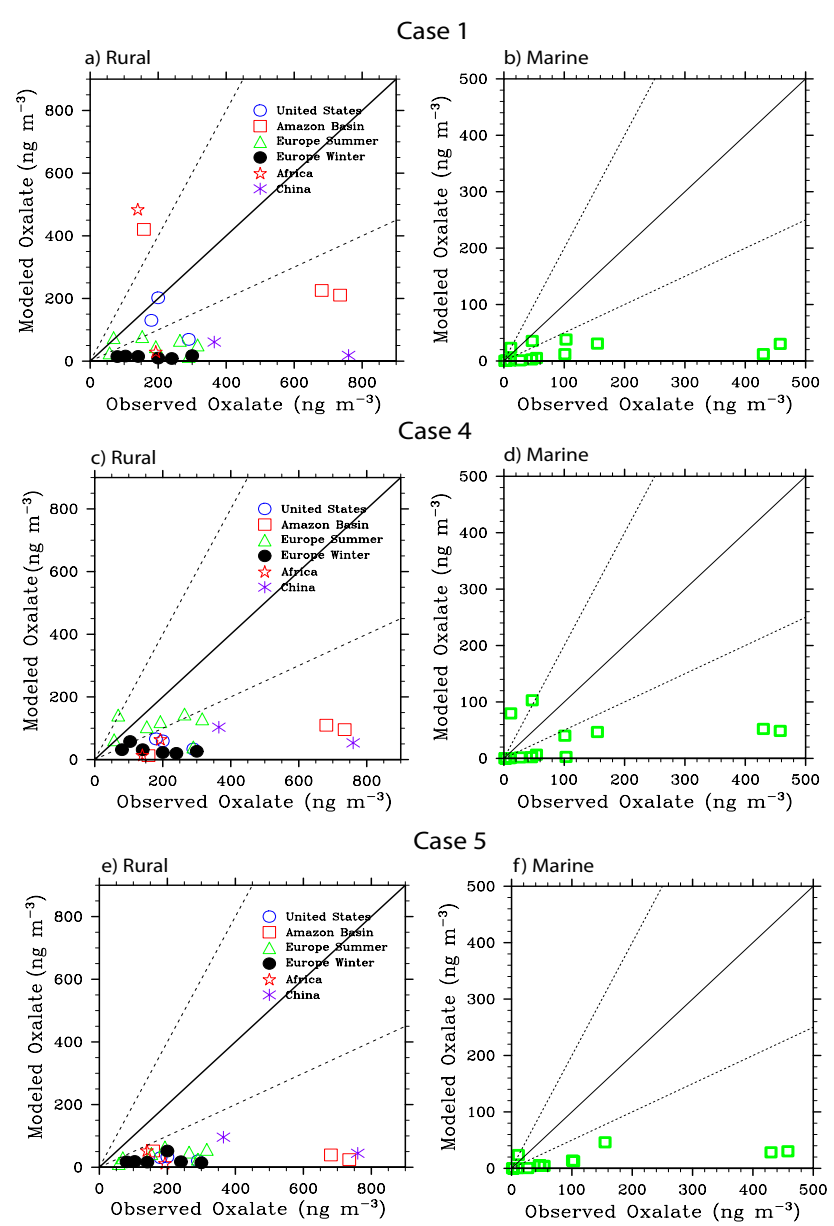

Figure 6. Comparison of the oxalate mass concentrations observed at rural and marine sites adopted from Table S3 of Myriokefalitakis et al. (2011) with the oxalic acid concentrations simulated in Case 1, Case 4, and Case 5. Solid lines show the 1:1 ratio, and dashed lines show the $1: 2$ and $2: 1$ ratios. The measurements at the various sites were made in different seasons and different years between 1980 and 2007 and most of them were reported with several days of sampling duration. The model results are the average values over the same months as the observations.

the site in Sydney, Florida, at which the model still underpredicts the oxalate source or/and overestimates its sink. For the two sites in Africa (red stars in Fig. 6), the model fails to predict the observations. The modeled oxalate concentration in Case 1 is 3 times higher than the observation at the central Africa site and is only about $1 / 5$ of measured concentration at the South Africa site. This might suggest that the cloud water content in this simulation is inconsistent with the real cloud water content or that the model does not represent the sources and/or sinks of oxalate over this region very well. In Case 4, the model underpredicts the measurements at both of these two sites.

When including Fe chemistry in cloud water in Case 5, almost all of the modeled oxalate concentrations are lower than 
the measurements by over a factor of 2 . As noted above, this underestimation may be caused by an overestimation of the photolytic rate of the $\mathrm{Fe}$ oxalate complex and/or an underestimation of oxalate production rate.

The global oxalate burden in Case S1 reported by Myriokefalitakis et al. (2011) is 5 times larger than the burden reported here for Case 1 . This is partly because Myriokefalitakis et al. (2011) increased the solubility of glyoxal and methylglyoxal in cloud water by 2 orders of magnitude, which is at the high end of measured values, causing a larger oxalate source. Myriokefalitakis et al. (2011) also included a set of additional reactions proposed by Carlton et al. (2007) which were based on experiments that were performed under higher glyoxal concentration conditions than those present in real cloud water. These additional reactions result in more oxalate formation. Myriokefalitakis et al. (2011) combined these additional reactions into a single reaction (see Reaction (R21) in Table 1 in Myriokefalitakis et al., 2011). We note that the reaction rate constant of $3.1 \times 10^{9} \mathrm{~L} \mathrm{~mol}^{-1} \mathrm{~s}^{-1}$ for that combined reaction was a typo (M. Kanakidou, personal communication, 2014). The reaction rate constant should be $3.1 \times 10^{10} \mathrm{~L} \mathrm{~mol}^{-1} \mathrm{~s}^{-1}$. In addition, a longer oxalate lifetime with respect to deposition was predicted by these authors. The larger oxalate burden in Myriokefalitakis et al. (2011) leads to a closer agreement with measurements over rural sites. However, the simulations in Myriokefalitakis et al. (2011) did not include Fe chemistry in cloud water which, as we have shown, can decrease oxalate concentrations significantly (compare Case 1 and Case 5).

Figure 6 also shows a comparison of oxalate with observations at marine sites. Most of the modeled oxalate is lower than the measurements. Myriokefalitakis et al. (2011) considered an extra glyoxal source of $20 \mathrm{Tg} \mathrm{yr}^{-1}$ over the oceans to explain the gap between the glyoxal measured by satellite and that predicted in their model. The underestimation of oxalate at marine sites in our model would also be improved by adding an extra marine source of glyoxal, although the origin of glyoxal in the marine boundary layer is still a matter of debate (Rinaldi et al., 2011). As shown above and in Sect. 3.4, cloud water has an important effect on oxalate formation. Therefore it is also valuable to compare the cloud water content in the model with that in the measurements. However, there are only a few sites where measured oxalate concentrations were reported together with cloud water content (e.g., Sorooshian et al., 2006; Wonaschuetz et al., 2012). Thus, this comparison is unlikely to be able to discern which source might explain the underestimate.

\subsection{AMS measurements}

Although there are no measurements available that can separate aqSOA from the SOA formed in the gas phase, we can compare the modeled total SOA with the observed total SOA. The predicted ratio of the global average aqSOA concentration to total SOA concentration ranges from $9.5 \%$ in Case 2 to $33.5 \%$ in Case 6. Zhang et al. (2007) present observational SOA data (measured by aerosol mass spectrometry, AMS) from a series of surface measurements at multiple sites in the Northern Hemisphere, which were made in different seasons and different years between 2000 and 2006 and were reported for the average of varying durations, spanning 8 to 36 days. Here, we compare the model data at the corresponding grid in the corresponding month. Figure 7 shows the comparisons of SOA between observations and predictions in Case 1, Case 2, Case 4, Case 5 and Case 6. The normalized mean bias (NMB) and correlation coefficient $(R)$ for these comparisons are listed in Table 6 . We do not show the comparisons for Case 3 in Fig. 7 because the SOA concentrations for this case are close to those for Case 2 (Table 2). Again, we do not expect the model with its low horizontal resolution to capture the POA emissions at urban sites, nor would we capture high local VOC and $\mathrm{NO}_{\mathrm{x}}$ emissions, which have a very complex effect on SOA formation due to non-linear chemistry (Stroud et al., 2011). The NMB in Case 1 is $-32.4 \%$ for rural sites (see the Table 6). The multiphase reaction scheme used for aqSOA in aerosol water in Case 2 leads to a larger underestimation (a NMB of around $-42.5 \%$ ); the use of the GFDL AM3 cloud field allows the model predictions to more closely match the measurements; the model in Case 6, which adopts the reactive uptake method for both aerosols and clouds, overestimates the observations by around $20 \%$.

In addition to the AMS measurements made in the Northern Hemisphere extra-tropics reported in Zhang et al. (2007), we also show the comparison with measurements from three different campaigns in tropical forested areas (Table 7). As SOA dominated the total submicron OA in the Amazon Basin (Chen et al., 2009) and in Malaysian Borneo (Robinson et al., 2011), the comparison of OA in these two sites reflects the model performance of SOA to a large extent. Compared with the measurements in west Africa reported by Capes et al. (2009), the model predicts both a higher SOA concentration and a higher $\mathrm{NO}_{\mathrm{x}}$ concentration. The $\mathrm{NO}_{\mathrm{x}}$ concentration has been shown to have a large effect on SOA formation (e.g., $\mathrm{Ng}$ et al., 2007), thus, we expect that improving the $\mathrm{NO}_{\mathrm{x}}$ predictions might lead to a better SOA simulation. There are two measurements available in the Amazon region. Gilardoni et al. (2011) reported average $\mathrm{PM}_{2.5}$ organic aerosol concentrations during the wet season (February-June) of $1.7 \mu \mathrm{g} \mathrm{m}^{-3}$, larger than the wet season concentrations measured at the same site by Chen et al. (2009) by about $60-80 \%$. In comparison with the measurements reported by Gilardoni et al. (2011), our simulated concentrations in Case 1 to Case 5 are around $60 \%$ too high. At the Malaysian Borneo site, the model simulations of SOA are higher than the observation by less than $40 \%$ for Case 1 to Case 5. The simulation in Case 6 overestimates the measurements by a factor of 3.8 at the West Africa site and by a 
Table 6. Normalized mean bias (NMB) and correlation coefficient $(R)$ between the predicted SOA for the simulations and observations reported by Zhang et al. (2007). The number of sites in the comparison is in parentheses.

\begin{tabular}{lcr|cr|rr}
\hline Case name & \multicolumn{2}{c|}{$\begin{array}{c}\text { Urban sites } \\
(N=14)\end{array}$} & \multicolumn{2}{c|}{$\begin{array}{c}\text { Urban downwind } \\
\text { sites }(N=6)\end{array}$} & \multicolumn{2}{c}{$\begin{array}{c}\text { Rural sites } \\
(N=17)\end{array}$} \\
\hline NMB & $R$ & NMB & $R$ & NMB & $R$ \\
\hline Case 1 & $-40.3 \%$ & 0.69 & $-37.6 \%$ & 0.87 & $-32.4 \%$ & 0.24 \\
Case 2 & $-49.2 \%$ & 0.71 & $-48.0 \%$ & 0.90 & $-42.5 \%$ & 0.28 \\
Case 3 & $-49.5 \%$ & 0.72 & $-48.3 \%$ & 0.89 & $-42.9 \%$ & 0.28 \\
Case 4 & $-28.1 \%$ & 0.63 & $-25.9 \%$ & 0.80 & $-13.8 \%$ & 0.25 \\
Case 5 & $-41.2 \%$ & 0.69 & $-38.4 \%$ & 0.85 & $-33.2 \%$ & 0.24 \\
Case 6 & $-12.5 \%$ & 0.72 & $+8.9 \%$ & 0.86 & $+20.0 \%$ & 0.30 \\
\hline
\end{tabular}

factor of over two at the Amazon and the Malaysian Borneo sites.

It should be noted that good agreement between observations and model predictions does not imply a robust understanding of underlying processes. However, the relative trends in how these comparisons change between different cases (Table 8) help one to understand the benefits of different underlying processes and to determine the best current approach. For the Northern Hemisphere, the uptake method (Case 1 and Case 6) provides an approach that agrees better with the observations while the use of the GFDL cloud field also improves the model performance. In the tropics the use of the multiphase reaction scheme helps to close the gap between the simulation and the observations, and including $\mathrm{Fe}$ chemistry also decreases the model bias. On the other hand, including Fe chemistry degrades the model's ability to predict the oxalate concentrations. Thus there is no single approach that is able to capture all the observations well. Further mechanism development and/or aerosol transport model and general circulation model development of cloud fields are needed to improve the agreement with observations. For example, the inclusion of stable $\mathrm{Ca}$ and $\mathrm{Zn}$ oxalate complex formation would increase both oxalate and SOA concentrations and thus help to close the gap between the simulation and the observations, as we noted above in Sect. 3.7.

\section{3 $\mathrm{O} / \mathrm{C}$ ratios}

It is useful to compare the $\mathrm{O} / \mathrm{C}$ ratio of our modeled $\mathrm{OA}$ to observations, since the $\mathrm{O} / \mathrm{C}$ ratio in aqueous formation mechanisms is expected to be larger than that in gas-phase formation mechanisms. Aiken et al. (2008) derived a significant correlation between the $\mathrm{O} / \mathrm{C}$ ratios of $\mathrm{OA}$ and their $f_{44}$ signal (the ratio of $m / z, 44$ to the total signal in the mass spectrum) and $\mathrm{Ng}$ et al. (2010) used this correlation to estimate the $\mathrm{O} / \mathrm{C}$ ratio of oxygenated OA (OOA) obtained from a factor analysis of the Northern Hemisphere AMS data set. Here, we compare the $\mathrm{O} / \mathrm{C}$ ratios estimated in the model with those reported by $\mathrm{Ng}$ et al. (2010) (Fig. 8).

In the model, we have four different SOA components: SOA from the gas-particle partitioning of semi-volatile or- ganic compounds (SVOCs), SOA from aerosol phase reactions of these condensed SVOCs, SOA from the uptake of epoxide on sulfate aerosol, and SOA formed in the aqueous phase as described above (aqSOA). We used the following methods to estimate the predicted $\mathrm{O} / \mathrm{C}$ ratio of these SOA components:

1. For the SOA from the gas-particle partitioning of SVOCs, there are 26 explicit SVOCs that contribute to the SOA formed from gas-particle partitioning. We calculated the $\mathrm{O} / \mathrm{C}$ ratio for each species based on their chemical formulas (see Table S1 in Lin et al., 2012).

2. For the SOA from aerosol phase reactions of condensed SVOCs, however, it is not as straightforward to calculate $\mathrm{O} / \mathrm{C}$ ratio. First, the aerosol phase reactions of condensed SVOCs were simply treated in the model as firstorder reactions to form oligomers with an assumed time constant (nominally 1 day), without any information on the products from these aerosol phase reactions. However, Chen et al. (2011) and Liu et al. (2012) suggested specific aerosol phase reactions for organic hydroperoxides and organic nitrate, respectively, both of which are major components of SVOCs in the model (Lin et al., 2012). Chen et al. (2011) proposed a set of new aerosol phase reactions for organic hydroperoxides: decomposition, followed by radical-radical oligomerization to explain the smaller measured $\mathrm{O} / \mathrm{C}$ ratios than those predicted in their model. This aerosol phase reaction was shown to remove 1-2 $\mathrm{O}$ atoms from organic hydroperoxides. Organic nitrate is thought to undergo hydrolysis in the particle phase (Liu et al., 2012), which removes $2 \mathrm{O}$ atoms from organic nitrate. Despite the simple treatment for oligomer formation in the model, we assume that the oligomers from organic hydroperoxides and organic nitrate have $1.5 \mathrm{O}$ atoms and $2 \mathrm{O}$ atoms less than condensed organic hydroperoxides and organic nitrate have, respectively, based on Chen et al. (2011) and Liu et al. (2012). For the oligomers formed from other condensed SVOCs, we assume they have the same $\mathrm{O} / \mathrm{C}$ ratio as their corresponding SVOCs. An additional 
Table 7. Comparison of simulated $\mathrm{OA}$ and $\mathrm{NO}_{\mathrm{x}}$ with observations in tropical forested regions.

\begin{tabular}{|c|c|c|c|c|c|}
\hline & & \multicolumn{2}{|c|}{ West Africa (below 2 km) } & \multirow{2}{*}{$\begin{array}{r}\begin{array}{r}\text { Amazon Basin } \\
\text { (surface) }\end{array} \\
\begin{array}{r}\text { Total OA } \\
\left(\mu \mathrm{g} \mathrm{m}^{-3}\right)\end{array}\end{array}$} & \multirow{2}{*}{$\begin{array}{r}\text { Malaysian Borneo } \\
(\text { surface })\end{array}$} \\
\hline & & $\begin{array}{l}\mathrm{NO}_{\mathrm{X}} \\
(\mathrm{ppt})\end{array}$ & $\begin{array}{r}\text { SOA } \\
\left(\mu \mathrm{g} \mathrm{m}^{-3}\right)\end{array}$ & & \\
\hline \multicolumn{2}{|l|}{ Observations } & $\begin{array}{r}210 \text { (Capes et } \\
\text { al., 2009) }\end{array}$ & $\begin{array}{r}1.18 \text { (Capes et } \\
\text { al., 2009) }\end{array}$ & $\begin{array}{r}0.7 \text { (Chen et } \\
\text { al., 2009) } \\
1.70 \text { (Gilardoni et } \\
\text { al., 2011) }\end{array}$ & $\begin{array}{r}0.74 \text { (Robinson et } \\
\text { al., 2011) }\end{array}$ \\
\hline \multirow{6}{*}{ Simulations } & Case 1 & 354 & 2.54 & 2.54 & 1.10 \\
\hline & Case 2 & 354 & 2.36 & 2.19 & 0.87 \\
\hline & Case 3 & 352 & 2.20 & 2.02 & 0.80 \\
\hline & Case 4 & 367 & 2.69 & 2.86 & 1.07 \\
\hline & Case 5 & 347 & 1.90 & 1.64 & 0.84 \\
\hline & Case 6 & 352 & 4.47 & 4.45 & 1.57 \\
\hline
\end{tabular}

Table 8. Comparison of the normalized mean bias (NMB) between observations and the model results for different cases.

\begin{tabular}{lrrr}
\hline & $\begin{array}{r}\text { AMS measurements } \\
\text { at rural sites in } \\
\text { Northern Hemisphere }\end{array}{ }^{1}$ tropical & $\begin{array}{r}\text { AMS } \\
\text { measurements in } \\
\text { regions }^{2}\end{array}$ & $\begin{array}{r}\text { Oxalate } \\
\text { measurements }\end{array}$ \\
\hline Case 1 & $-32.4 \%$ & $70.7 \%$ & $-63.1 \%$ \\
Case 2 & $-42.5 \%$ & $49.7 \%$ & $-61.2 \%$ \\
Case 3 & $-42.9 \%$ & $38.7 \%$ & $-62.2 \%$ \\
Case 4 & $-13.8 \%$ & $82.9 \%$ & $-76.2 \%$ \\
Case 5 & $-33.2 \%$ & $19.3 \%$ & $-88.2 \%$ \\
Case 6 & $+20.0 \%$ & $189.7 \%$ & N/A \\
\hline${ }^{1}$ Reported by Zhang et al. (2007); & & \\
${ }^{2}$ reported by Capes et al. (2009), Gilardoni et al. (2011), and Robinson et al. (2011); & \\
${ }^{3}$ compiled by Myriokefalitakis et al. (2011).
\end{tabular}

complexity is that in the model the 26 SOA species formed from the oligomerization of condensed SVOCs are combined into one species when they are transported in the atmosphere. Therefore, we used their global averaged SOA formation rates (listed in Table S1 in Lin et al., 2012) rather than their mass concentrations to weight their relative contributions to the $\mathrm{O} / \mathrm{C}$ ratio. Based on these assumptions, we estimate the average $\mathrm{O} / \mathrm{C}$ ratio for the SOA from aerosol phase reactions of condensed SVOCs to be around 0.687. However, values for some of the SVOCs with smaller burdens ranges from 3.0 to 0.3 .

3. For SOA from the uptake of epoxide, the $\mathrm{O} / \mathrm{C}$ ratio is estimated to be 0.6 since the $\mathrm{O} / \mathrm{C}$ ratio of epoxide from isoprene oxidation is 0.6 in the model, and its oligomerization would not be expected to change this ratio (Surratt et al., 2010).

4. The $\mathrm{O} / \mathrm{C}$ ratio for oxalic acid is 2 , for glyoxylic acid is 1.5 , and for pyruvic acid is 1.0 . The $\mathrm{O} / \mathrm{C}$ ratio for oligomers from glyoxal and methylglyoxal is assumed to be 1.5 , which is consistent with the measurements by Lim et al. (2010).

We then averaged the $\mathrm{O} / \mathrm{C}$ ratios of these four SOA components by weighting their mass concentrations to obtain the average $\mathrm{O} / \mathrm{C}$ ratio for total SOA. As shown in Fig. 8, the modeled $\mathrm{O} / \mathrm{C}$ ratios are higher than those reported by $\mathrm{Ng}$ et al. (2010) and have a normalized mean bias of $33 \%$. The higher $\mathrm{O} / \mathrm{C}$ ratios estimated in the model might suggest an overestimation of the contribution of aqueous SOA formation or multiple generation oxidation products to SOA formation or a missing aerosol phase reaction of condensed SVOCs that would lead to products with lower $\mathrm{O} / \mathrm{C}$ ratios. Alternatively, the AMS instrument might underestimate $\mathrm{O} / \mathrm{C}$ ratios.

\section{Conclusions}

In this paper, we simulated the formation of SOA in both cloud and aerosol water using multiphase processes with different chemical reactions as well as a surface-limited uptake process. We also conducted a simulation using the GFDL 

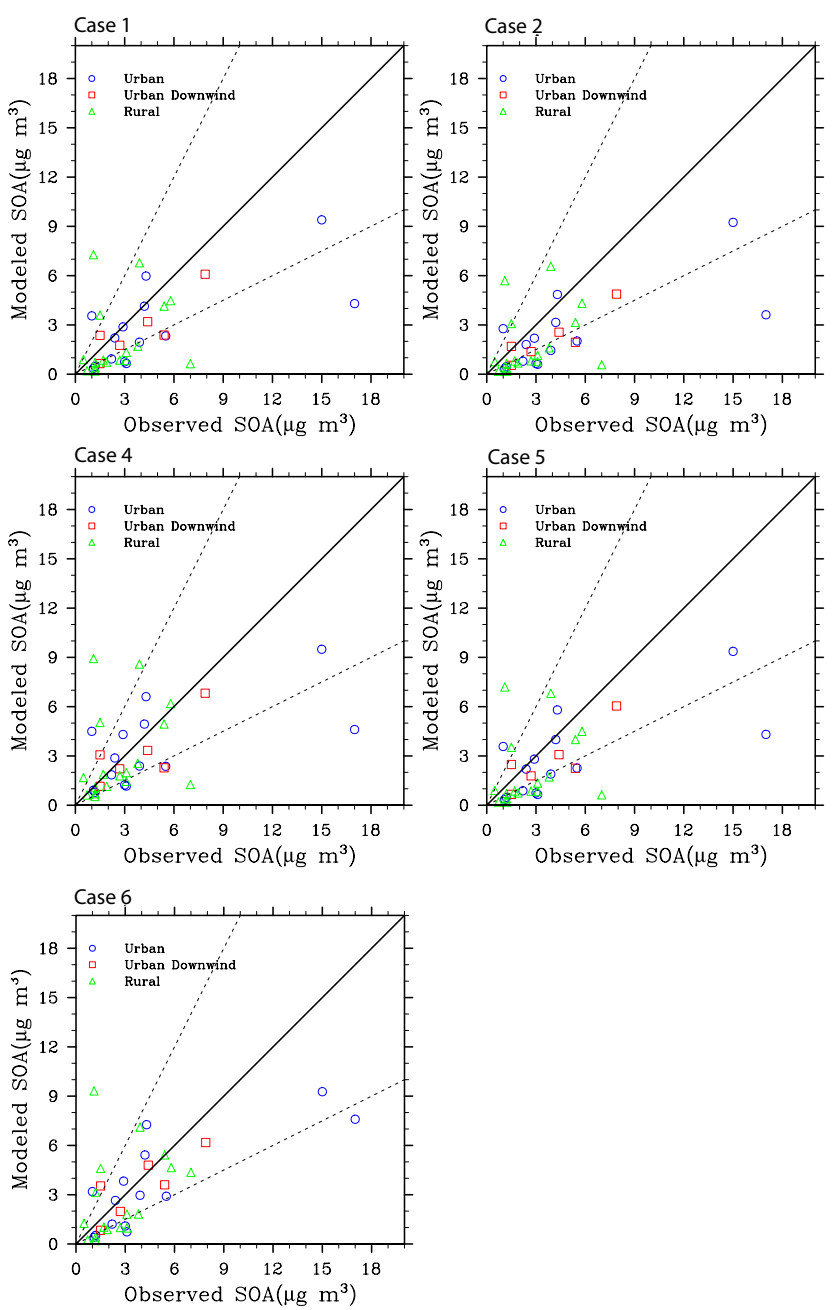

Figure 7. Comparison of SOA mass concentrations observed at the urban, urban downwind and rural sites reported in Zhang et al. (2007) with those simulated in Case 1, Case 2, Case 4, Case 5 and Case 6. Solid lines show the $1: 1$ ratio, and dashed lines show the $1: 2$ and $2: 1$ ratios. The measurements at the various sites were made in different seasons and different years between 2000 and 2006 and were reported for the average of different durations, spanning 8 to 36 days. The model results are the average values over the same months as the observations.

AM3 cloud fields and a simulation including Fe chemistry in cloud water.

The annual average organic acid concentration (i.e., the sum of oxalic acid, glyoxylic acid, and pyruvic acid) peaks over the tropics due to the large biogenic emissions and abundant cloud water there, while oligomers generally show a maxima over industrialized areas in the Northern Hemisphere due to formation within aqueous aerosols and the large sulfate aerosol concentrations located in these regions. During the summer, large organic acid concentrations are also predicted in the Northern Hemisphere resulting from seasonally enhanced biogenic emissions and photochemistry.

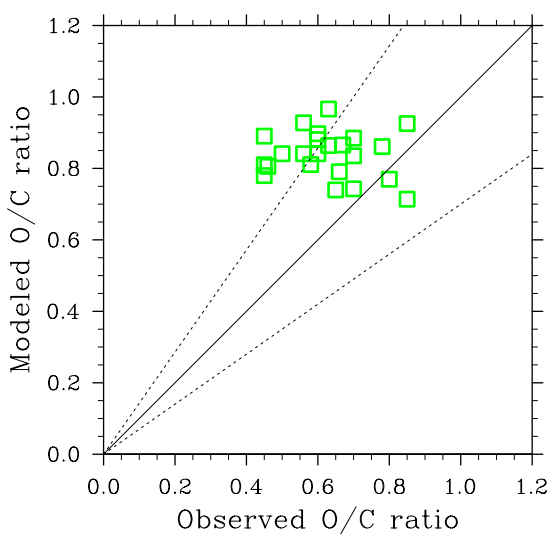

Figure 8. Comparison of O/C ratio estimated by $\mathrm{Ng}$ et al. (2010) for urban downwind, rural and remote sites with those simulated in Case 1. The values for other cases are similar to those in Case 1. Solid lines show the $1: 1$ ratio, and dashed lines show the $10: 7$ and $7: 10$ ratios, which roughly corresponds to the uncertainty of the AMS measurements, stated as $30 \%$ for the $\mathrm{O} / \mathrm{C}$ ratio (Aiken et al., 2008). The measurements at the various sites were made in different seasons and different years between 2000 and 2009 and were reported for the average of different durations, spanning 8 to 36 days. The model results are the average values over the same months as the observations.

Similarly, the oligomer concentrations increase in the summer.

Using the surface-limited uptake process scheme with the reactive uptake parameter adopted from the laboratory studies (Case 6) leads to higher aqSOA production rates both in cloud and in aerosol water than using only the multiphase process scheme (Cases 2 and 3). The use of a multiphase reaction scheme for aerosol water decreases the global total aqSOA burden by around $50 \%$ (compare Case 1 and Case 2). The use of the uptake parameter method for both cloud water and aerosol water in Case 6 predicts a $185 \%$ larger burden than Case 1. An increase of 3 orders of magnitude for the effective Henry's law constants of glyoxal and methylglyoxal in aerosol water leads to an increase of 1 order of magnitude in oligomer net production rate and an increase in aqSOA burden by $8 \%$. When we changed the diagnostic cloud field to that simulated by the GFDL AM3 model, the organic acid production rate decreased by around $60 \%$ while sulfate formation rates increased slightly, because the GFDL AM3 cloud field has a much smaller cloud water content in tropical regions but a higher cloud water content in the Northern Hemisphere. The replacement of the diagnostic cloud field with the GFDL AM3 cloud field causes the aqSOA burden to increase by $16 \%$. The aqSOA formation rate in cloud water is slightly less than in aerosol water in the simulation with the GFDL AM3 cloud field, while in the other simulations with the diagnostic cloud field the aqSOA formation rate in cloud water dominates that in aerosol water. The introduction of Fe chemistry in cloud water has a large impact on the 
aqueous-phase $\mathrm{OH}$ and aqSOA budget, increasing the global average tropical aqueous $\mathrm{OH}$ radical source by a factor of about 2.6 and decreasing the net source and burden of aqSOA by $31 \%$ and $11 \%$, respectively.

We also compared the oxalic acid predicted from these different schemes and chemical mechanisms with measurements obtained in Europe, the Amazon, Africa, China and the US. Overall, the model tends to underestimate observations, probably because it does not account for the direct emission of oxalic acid from primary sources (e.g., wood burning, meat cooking, and biomass burning) or the oxalic acid formed in the aging process associated with emissions plumes. However, this underestimation might also be due to a deposition rate that is too high or to a cloud water content that is too low in the model. In fact, using the GFDL AM3 cloud field in Case 4 improved the model predictions at some sites in the Northern Hemisphere. Consistent with the findings of Myriokefalitakis et al. (2011) and Rinaldi et al. (2011), the comparison of oxalate for marine sites suggests that there may be a missing source of oxalic acid over the ocean. When including Fe chemistry in cloud water, the model underpredicts all of the measured concentrations of oxalate by over a factor of 2.

Comparisons of the total SOA (aqSOA combined with the SOA formed in the gas phase) for all cases with the SOA measured by AMS in the Northern Hemisphere show reasonable agreement, although the NMB varies between $+20 \%$ in Case 6 (which used a surface-based uptake coefficient method for aqSOA for both cloud and aerosol water) to around $-42 \%$ in Cases 2 and 3 (which used a complete or a parameterized multiphase reaction scheme for aqSOA). While Case 6 overestimates the observations by a factor of over 3 at a west Africa site and by over a factor of 2 at the two other tropical sites, adopting the multiphase reaction scheme for aqSOA decreases the disagreement to within a factor of 2 at all three sites. In addition to the SOA mass measured by AMS, we compared the $\mathrm{O} / \mathrm{C}$ ratio of OOA estimated based on a factor analysis of AMS measurements to the $\mathrm{O} / \mathrm{C}$ ratio of modeled SOA based on some simple assumptions. The estimated $\mathrm{O} / \mathrm{C}$ ratios from the model are somewhat higher than those estimated from the measurements, which might indicate that the model somewhat overestimates the contribution of aged organic species and/or aqueous SOA formation to the total SOA formation.

In our study, we were unable to find a single mechanism that is able to capture all observations well. The cases that use an uptake coefficient method for aerosol water perform better than the cases using the multiphase reaction scheme in comparison to the Northern Hemisphere AMS measurements. However, in the tropics, the use of a multiphase process scheme for both aerosol water and cloud water perform best, while the case using the uptake coefficient method in cloud water clearly overestimates the observed OA by more than a factor 3 . The multiphase reaction scheme including Fe chemistry underpredicts the observed oxalate concentra- tions at all sites. Since the inclusion of the formation of stable metal-oxalate complexes in the model is expected to enhance both oxalate and aqSOA concentrations, a multiphase reaction scheme that included this complex formation might work best.

Future work is needed to close the gap between simulations and observations. In particular, more lab and model studies are needed to improve the representation of chemical reactions within the aqueous phase and at the gas-aerosol interface, since there is still a large inconsistency between the existing uptake parameter method and the multiphase reaction schemes derived from lab studies and field measurements. Also, more work is needed to improve our understanding of oxalate sources and sinks, especially the formation of stable metal-oxalate complexes, because the model tended to underestimate observed oxalate concentrations for all cases studied. In addition, the high sensitivity of aqSOA to cloud water content shows the importance of improving the representation of cloud water content in general circulation models in order to improve aqSOA formation.

\section{The Supplement related to this article is available online at doi:10.5194/acp-14-5451-2014-supplement.}

Acknowledgements. The authors are grateful for support by the Department of Energy (DOE) Earth System Modeling program through grant number DOE FG02 01 ER63248, support from the DOE Atmospheric Science Research Program through grant number DoE DE-SC0008486, and support from EPA Science to Achieve Results (STAR) program, grant \#R-83337701. A. Ito's work at JAMSTEC was supported under Program for Risk Information on Climate Change by MEXT. The authors thank B. J. Turpin for her helpful suggestions on improving the manuscript as well as the two anonymous reviewers.

Edited by: A. Carlton

\section{References}

Aiken, A. C., DeCarlo, P. F., Kroll, J. H., Worsnop, D. R., Huffman, J. A., Docherty, K. S., Ulbrich, I. M., Mohr, C., Kimmel, J. R., Sueper, D., Sun, Y., Zhang, Q., Trimborn, A., Northway, M., Ziemann, P. J., Canagaratna, M. R., Onasch, T. B., Alfarra, M. R., Prevot, A. S. H., Dommen, J., Duplissy, J., Metzger, A., Baltensperger, U., and Jimenez, J. L.: O/C and OM/OC Ratios of Primary, Secondary, and Ambient Organic Aerosols with HighResolution Time-of-Flight Aerosol Mass Spectrometry, Environ. Sci. Technol., 42, 4478-4485, doi:10.1021/es703009q, 2008.

Altieri, K. E., Seitzinger, S. P., Carlton, A. G., Turpin, B. J., Klein, G. C., and Marshall, A. G.: Oligomers formed through in-cloud methylglyoxal reactions: Chemical composition, properties, and mechanisms investigated by ultra-high resolution FT-ICR mass spectrometry, Atmos. Environ., 42, 1476-1490, doi:10.1016/j.atmosenv.2007.11.015, 2008. 
Arakaki, T., Anastasio, C., Kuroki, Y., Nakajima, H., Okada, K., Kotani, Y., Handa, D., Azechi, S., Kimura, T., Tsuhako, A., and Miyagi, Y.: A General Scavenging Rate Constant for Reaction of Hydroxyl Radical with Organic Carbon in Atmospheric Waters, Environ. Sci. Technol., 47, 8196-8203, doi:10.1021/es401927b, 2013.

Barth, M. C., Sillman, S., Hudman, R., Jacobson, M. Z., Kim, C. H., Monod, A., and Liang, J.: Summary of the cloud chemistry modeling intercomparison: photochemical box model simulation, J. Geophys. Res.-Atmos., 108, 4214, doi:10.1029/2002JD002673, 2003.

Blando, J. D. and Turpin, B. J.: Secondary organic aerosol formation in cloud and fog droplets: a literature evaluation of plausibility, Atmos. Environ., 34, 1623-1632, 2000.

Brooks, S. D., Wise, M. E., Cushing, M., and Tolbert, M. A.: Deliquescence behavior of organic/ammonium sulfate aerosol, J. Geophys. Res., 29, 1917, doi:10.1029/2002GL014733, 2002.

Capes, G., Murphy, J. G., Reeves, C. E., McQuaid, J. B., Hamilton, J. F., Hopkins, J. R., Crosier, J., Williams, P. I., and Coe, H.: Secondary organic aerosol from biogenic VOCs over West Africa during AMMA, Atmos. Chem. Phys., 9, 3841-3850, doi:10.5194/acp-9-3841-2009, 2009.

Carlton, A. G., Turpin, B. J., Lim, H. J., Altieri, K. E., and Seitzinger, S.: Link between isoprene and secondary organic aerosol (SOA): Pyruvic acid oxidation yields low volatility organic acids in clouds, Geophys. Res. Lett., 33, L06822, doi:10.1029/2005GL025374, 2006.

Carlton, A. G., Turpin, B. J., Altieri, K. E., Seitzinger, S., Reff, A., Lim, H. J., and Ervens, B.: Atmospheric oxalic acid and SOA production from glyoxal: Results of aqueous photooxidation experiments, Atmos. Environ., 41, 7588-7602, doi:10.1016/j.atmosenv.2007.05.035, 2007.

Carlton, A. G., Turpin, B. J., Altieri, K. E., Seitzinger, S. P., Mathur, R., Roselle, S. J., and Weber, R. J.: CMAQ model performance enhanced when in-cloud secondary organic aerosol is included: Comparisons of organic carbon predictions with measurements, Environ. Sci. Technol., 42, 8789-8802, 2008.

Chen, J., Griffin, R. J., Grini, A., and Tulet, P.: Modeling secondary organic aerosol formation through cloud processing of organic compounds, Atmos. Chem. Phys., 7, 5343-5355, doi:10.5194/acp-7-5343-2007, 2007.

Chen, Q., Farmer, D. K., Schneider, J., Zorn, S. R., Heald, C. L., Karl, T. G., Guenther, A., Allan, J. D., Robinson, N., Coe, H., Kimmel, J. R., Pauliquevis, T., Borrmann, S., Pöschl, U., Andreae, M. O., Artaxo, P., Jimenez, J. L., and Martin, S. T.: Mass spectral characterization of submicron biogenic organic particles in the Amazon Basin, Geophys. Res. Lett., 36, L20806, doi:10.1029/2009g1039880, 2009.

Chen, Q., Liu, Y., Donahue, N. M., Shilling, J. E., and Martin, S. T.: Particle-Phase Chemistry of Secondary Organic Material: Modeled Compared to Measured O : C and H:C Elemental Ratios Provide Constraints, Environ. Sci. Technol., 45, 4763-4770, doi:10.1021/es104398s, 2011.

Coy, L. and Swinbank, R.: Characteristics of stratospheric winds and temperatures produced by data assimilation, J. Geophys. Res., 102, 25763-25781, 1997.

Coy, L., Nash, E. R., and Newman, P. A.: Meteorology of the polar vortex: Spring 1997, Geophys. Res. Lett., 24, 2693-2696, 1997.
DeGouw, J. A., Middlebrook, A. M., Warneke, C., Goldan, P. D., Kuster, W. C., Roberts, J. M., Fehsenfeld, F. C., Worsnop, D. R., Canagaratna, M. R., Pszenny, A. A. P., Keene, W. C., Marchewka, M., Bertram, S. B., and Bates, T. S.: Budget of organic carbon in a polluted atmosphere: Results from the New England Air Quality Study in 2002, J. Geophys. Res., 110, D16305, doi:10.1029/2004JD005623, 2005.

Deguillaume, L., Leriche, M., and Desboeufs, K.: Transition metals in atmospheric liquid phases: Sources, reactivity, and sensitive parameters, Chemical Reviews-Columbus, 105, 3388-3431, 2005.

Deguillaume, L., Desboeufs, K. V., Leriche, M., Long, Y., and Chaumerliac, N.: Effect of iron dissolution on cloud chemistry: from laboratory measurements to model results, Atmos. Pollut. Res., 1, 220-228, 2010.

Donner, L. J., Wyman, B. L., Hemler, R. S., Horowitz, L. W., Ming, Y., Zhao, M., Golaz, J.-C., Ginoux, P., Lin, S. J., Schwarzkopf, D. M., Austin, J., Alaka, G., Cooke, W. F., Delworth, T. L., Freidenreich, S. M., Gordon, C. T., Griffies, S. M., Held, I. M., Hurlin, W. J., Klein, S. A., Knutson, T. R., Langenhorst, A. R., Lee, H.C., Lin, Y., Magi, B. I., Malyshev, S. L., Milly, P. C. D., Naik, V., Nath, M. J., Pincus, R., Ploshay, J. J., Ramaswamy, V., Seman, C. J., Shevliakova, E., Sirutis, J. J., Stern, W. F., Stouffer, R. J., Wilson, R. J., Winton, M., Wittenberg, A. T., and Zeng, F.: The Dynamical Core, Physical Parameterizations, and Basic Simulation Characteristics of the Atmospheric Component AM3 of the GFDL Global Coupled Model CM3, J. Climate, 24, 3484-3519, doi:10.1175/2011JCLI3955.1, 2011.

Dzepina, K., Volkamer, R. M., Madronich, S., Tulet, P., Ulbrich, I. M., Zhang, Q., Cappa, C. D., Ziemann, P. J., and Jimenez, J. L.: Evaluation of recently-proposed secondary organic aerosol models for a case study in Mexico City, Atmos. Chem. Phys., 9, 5681-5709, doi:10.5194/acp-9-5681-2009, 2009.

El Haddad, I., Yao Liu, Nieto-Gligorovski, L., Michaud, V., Temime-Roussel, B., Quivet, E., Marchand, N., Sellegri, K., and Monod, A.: In-cloud processes of methacrolein under simulated conditions - Part 2: Formation of secondary organic aerosol, Atmos. Chem. Phys., 9, 5107-5117, doi:10.5194/acp-9-5107-2009, 2009.

Eliason, T. L., Aloisio, S., Donaldson, D. J., Cziczo, D. J., and Vaida, V.: Processing of unsaturated organic acid films and aerosols by ozone, Atmos. Environ., 37, 2207-2219, doi:10.1016/S1352-2310(03)00149-3, 2003.

Ervens, B. and Volkamer, R.: Glyoxal processing by aerosol multiphase chemistry: towards a kinetic modeling framework of secondary organic aerosol formation in aqueous particles, Atmos. Chem. Phys., 10, 8219-8244, doi:10.5194/acp-10-8219-2010, 2010.

Ervens, B., George, C., Williams, J. E., Buxton, G. V., Salmon, G. A., Bydder, M., Wilkinson, F., Dentener, F., Mirabel, P., Wolke, R., and Herrmann, H.: CAPRAM 2.4 (MODAC mechanism): An extended and condensed tropospheric aqueous phase mechanism and its application, J. Geophys. Res., 108, 4426, doi:10.1029/2002JD002202, 2003.

Ervens, B., Carlton, A. G., Turpin, B. J., Altieri, K. E., Kreidenweis, S. M., and Feingold, G.: Secondary organic aerosol yields from cloud processing of isoprene oxidation products, Geophys. Res. Lett., 35, L02816, doi:10.1029/2007gl031828, 2008. 
Ervens, B., Turpin, B. J., and Weber, R. J.: Secondary organic aerosol formation in cloud droplets and aqueous particles (aqSOA): a review of laboratory, field and model studies, Atmos. Chem. Phys., 11, 11069-11102, doi:10.5194/acp-1111069-2011, 2011.

Falkovich, A. H., Graber, E. R., Schkolnik, G., Rudich, Y., Maenhaut, W., and Artaxo, P.: Low molecular weight organic acids in aerosol particles from Rondônia, Brazil, during the biomassburning, transition and wet periods, Atmos. Chem. Phys., 5, 781797, doi:10.5194/acp-5-781-2005, 2005.

Feng, Y. and Penner, J. E.: Global modeling of nitrate and ammonium: Interaction of aerosols and tropospheric chemistry, J. Geophys. Res., 112, D01304, doi:10.1029/2005JD006404, 2007.

Fu, T. M., Jacob, D. J., Wittrock, F., Burrows, J. P., Vrekoussis, M., and Henze, D. K.: Global budgets of atmospheric glyoxal and methylglyoxal, and implications for formation of secondary organic aerosols, J. Geophys. Res., 113, D15303, doi:10.1029/2007jd009505, 2008.

Fu, T. M., Jacob, D. J., and Heald, C. L.: Aqueous-phase reactive uptake of dicarbonyls as a source of organic aerosol over eastern North America, Atmos. Environ., 43, 1814-1822, 2009.

Furukawa, T. and Takahashi, Y.: Oxalate metal complexes in aerosol particles: implications for the hygroscopicity of oxalatecontaining particles, Atmos. Chem. Phys., 11, 4289-4301, doi:10.5194/acp-11-4289-2011, 2011.

Gao, S., Hegg, D. A., Hobbs, P. V., Kirchstetter, T. W., Magi, B. I., and Sadilek, M.: Water-soluble organic components in aerosols associated with savanna fires in southern Africa: Identification, evolution, and distribution, J. Geophys. Res., 108, 8491, doi:10.1029/2002JD002324, 2003.

Ghan, S. J. and Zaveri, R. A.: Parameterization of optical properties for hydrated internally mixed aerosol, J. Geophys. Res., 112, D10201, doi:10.1029/2006JD007927, 2007.

Gilardoni, S., Vignati, E., Marmer, E., Cavalli, F., Belis, C., Gianelle, V., Loureiro, A., and Artaxo, P.: Sources of carbonaceous aerosol in the Amazon basin, Atmos. Chem. Phys., 11, $2747-$ 2764, doi:10.5194/acp-11-2747-2011, 2011.

Graham, B., Mayol-Bracero, O. L., Guyon, P., Roberts, G. C., Decesari, S., Facchini, M. C., Artaxo, P., Maenhaut, W., Koll, P., and Andreae, M. O.: Water-soluble organic compounds in biomass burning aerosols over Amazonia1. Characterization by NMR and GC-MS, J. Geophys. Res., 107, 8047, doi:10.1029/2001JD000336, 2002.

Hack, J. J.: Sensitivity of the Simulated Climate to a Diagnostic Formulation for Cloud Liquid Water, J. Climate, 11, 1497-1515, 1998.

He, C., Liu, J., Carlton, A. G., Fan, S., Horowitz, L. W., Levy II, H., and Tao, S.: Evaluation of factors controlling global secondary organic aerosol production from cloud processes, Atmos. Chem. Phys., 13, 1913-1926, doi:10.5194/acp-13-1913-2013, 2013.

He, N. and Kawamura, K.: Distributions and diurnal changes of low molecular weight organic acids and $\alpha$-dicarbonyls in suburban aerosols collected at Mangshan, North China, Geochem. J., 44, e17-e22, 2010.

Heald, C. L., Jacob, D. J., Park, R. J., Russell, L. M., Huebert, B. J., Seinfeld, J. H., Liao, H., and Weber, R. J.: A large organic aerosol source in the free troposphere missing from current models, Geophys. Res. Lett., 32, L18809, doi:10.1029/2005GL023831, 2005.
Herrmann, H.: Kinetics of aqueous phase reactions relevant for atmospheric chemistry, Chem. Rev., 103, 4691-4716, 2003.

Herrmann, H., Tilgner, A., Barzaghi, P., Majdik, Z., Gligorovski, S., Poulain, L., and Monod, A.: Towards a more detailed description of tropospheric aqueous phase organic chemistry: CAPRAM 3.0, Atmos. Environ., 39, 4351-4363, doi:10.1016/j.atmosenv.2005.02.016, 2005.

Herzog, M., Weisenstein, D. K., and Penner, J. E.: A dynamic aerosol module for global chemical transport models: Model description, J. Geophys. Res., 109, D18202, doi:10.1029/2003JD004405, 2004.

Hodzic, A., Jimenez, J. L., Madronich, S., Canagaratna, M. R., DeCarlo, P. F., Kleinman, L., and Fast, J.: Modeling organic aerosols in a megacity: potential contribution of semi-volatile and intermediate volatility primary organic compounds to secondary organic aerosol formation, Atmos. Chem. Phys., 10, 5491-5514, doi:10.5194/acp-10-5491-2010, 2010.

Ito, A. and Feng, Y.: Role of dust alkalinity in acid mobilization of iron, Atmos. Chem. Phys., 10, 9237-9250, doi:10.5194/acp-109237-2010, 2010.

Ito, A. and Xu, L.: Response of acid mobilization of iron-containing mineral dust to improvement of air quality projected in the future, Atmos. Chem. Phys., 14, 3441-3459, doi:10.5194/acp-14-34412014, 2014.

Ito, A., Sillman, S., and Penner, J. E.: Effects of additional nonmethane volatile organic compounds, organic nitrates, and direct emissions of oxygenated organic species on global tropospheric chemistry, J. Geophys. Res., 112, D06309, doi:10.1029/2005JD006556, 2007.

Jacob, D. J.: Chemistry of $\mathrm{OH}$ in remote clouds and its role in the production of formic acid and peroxymonosulfate, J. Geophys. Res., 91, 9807-9826, doi:10.1029/JD091iD09p09807, 1986.

Jimenez, J. L., Canagaratna, M. R., Donahue, N. M., Prevot, A. S. H., Zhang, Q., Kroll, J. H., DeCarlo, P. F., Allan, J. D., Coe, H., Ng, N. L., Aiken, A. C., Docherty, K. S., Ulbrich, I. M., Grieshop, A. P., Robinson, A. L., Duplissy, J., Smith, J. D., Wilson, K. R., Lanz, V. A., Hueglin, C., Sun, Y. L., Tian, J., Laaksonen, A., Raatikainen, T., Rautiainen, J., Vaattovaara, P., Ehn, M., Kulmala, M., Tomlinson, J. M., Collins, D. R., Cubison, M J., Dunlea, E. J., Huffman, J. A., Onasch, T. B., Alfarra, M. R., Williams, P. I., Bower, K., Kondo, Y., Schneider, J., Drewnick, F., Borrmann, S., Weimer, S., Demerjian, K., Salcedo, D., Cottrell, L., Griffin, R., Takami, A., Miyoshi, T., Hatakeyama, S., Shimono, A., Sun, J. Y., Zhang, Y. M., Dzepina, K., Kimmel, J. R., Sueper, D., Jayne, J. T., Herndon, S. C., Trimborn, A. M., Williams, L. R., Wood, E. C., Middlebrook, A. M., Kolb, C. E., Baltensperger, U., and Worsnop, D. R.: Evolution of Organic Aerosols in the Atmosphere, Science, 326, 1525-1529, 2009.

Johnson, M. S. and Meskhidze, N.: Atmospheric dissolved iron deposition to the global oceans: effects of oxalate-promoted $\mathrm{Fe}$ dissolution, photochemical redox cycling, and dust mineralogy, Geosci. Model Dev., 6, 1137-1155, doi:10.5194/gmd-6-11372013, 2013.

Kampf, C. J., Waxman, E. M., Slowik, J. G., Dommen, J., Pfaffenberger, L., Praplan, A. P., Prevot, A. S. H., Baltensperger, U., Hoffmann, T., and Volkamer, R.: Effective Henry's law partitioning and the salting constant of glyoxal in aerosols containing sulfate, Environ. Sci. Technol., 43, 4236-4244, 2013. 
Kroll, J. H., Ng, N. L., Murphy, S. M., Varutbangkul, V., Flagan, R. C., and Seinfeld, J. H.: Chamber studies of secondary organic aerosol growth by reactive uptake of simple carbonyl compounds, J. Geophys. Res., 110, D23207, doi:10.1029/2005JD006004, 2005.

Kundu, S., Kawamura, K., Lee, M., Andreae, T. W., Hoffer, A., and Andreae, M. O.: Comparison of Amazonian biomass burning and East Asian marine aerosols: Bulk organics, diacids and related compounds, water-soluble inorganic ions, stable carbon and nitrogen isotope ratios, Low Temp. Sci., 68, 89-100, 2010.

Lee-Taylor, J., Madronich, S., Aumont, B., Baker, A., Camredon, M., Hodzic, A., Tyndall, G. S., Apel, E., and Zaveri, R. A.: Explicit modeling of organic chemistry and secondary organic aerosol partitioning for Mexico City and its outflow plume, Atmos. Chem. Phys., 11, 13219-13241, doi:10.5194/acp-1113219-2011, 2011.

Legrand, M., Preunkert, S., Oliveira, T., Pio, C. A., Hammer, S., Gelencsér, A., Kasper-Giebl, A., and Laj, P.: Origin of $\mathrm{C}_{2}-\mathrm{C}_{5}$ dicarboxylic acids in the European atmosphere inferred from yearround aerosol study conducted at a west-east transect, J. Geophys. Res., 112, D23S07, doi:10.1029/2006JD008019, 2007.

Lelieveld, J. and Crutzen, P. J.: The role of clouds in tropospheric photochemistry, J. Atmos. Chem., 12, 229-267, doi:10.1007/BF00048075, 1991.

Liggio, J., Li, S. M., and McLaren, R.: Heterogeneous reactions of glyoxal on particulate matter: Identification of acetals and sulfate esters, Environ. Sci. Technol., 39, 1532-1541, 2005.

Lim, H. J., Carlton, A. G., and Turpin, B. J.: Isoprene forms secondary organic aerosol through cloud processing: model simulations, Environ. Sci. Technol., 9, 4441-4446, 2005.

Lim, Y. B., Tan, Y., Perri, M. J., Seitzinger, S. P., and Turpin, B. J.: Aqueous chemistry and its role in secondary organic aerosol (SOA) formation, Atmos. Chem. Phys., 10, 1052110539, doi:10.5194/acp-10-10521-2010, 2010.

Lim, Y. B., Tan, Y., and Turpin, B. J.: Chemical insights, explicit chemistry, and yields of secondary organic aerosol from $\mathrm{OH}$ radical oxidation of methylglyoxal and glyoxal in the aqueous phase, Atmos. Chem. Phys., 13, 8651-8667, doi:10.5194/acp-13-86512013, 2013.

Lin, G., Penner, J. E., Sillman, S., Taraborrelli, D., and Lelieveld, J.: Global modeling of SOA formation from dicarbonyls, epoxides, organic nitrates and peroxides, Atmos. Chem. Phys., 12, 47434774, doi:10.5194/acp-12-4743-2012, 2012.

Liu, J., Horowitz, L. W., Fan, S., Carlton, A. G., and Levy II, H.: Global in-cloud production of secondary organic aerosols: Implementation of a detailed chemical mechanism in the GFDL atmospheric model AM3, J. Geophys. Res., 117, D15303, doi:10.1029/2012JD017838, 2012.

Liu, S., Shilling, J. E., Song, C., Hiranuma, N., Zaveri, R. A., and Russell, L. M.: Hydrolysis of organonitrate functional groups in aerosol particles, Aerosol Sci. Technol., 46, 1359-1369, 2012.

Liu, X., Mauersberger, G., and Möller, D.: The effects of cloud processes on the tropospheric photochemistry: An improvement of the eurad model with a coupled gaseous and aqueous chemical mechanism, Atmos. Environ., 31, 3119-3135, doi:10.1016/S1352-2310(97)00057-5, 1997.

Liu, X. H. and Penner, J. E.: Effect of Mount Pinatubo $\mathrm{H}_{2} \mathrm{SO}_{4} / \mathrm{H}_{2} \mathrm{O}$ aerosol on ice nucleation in the upper troposphere using a global chemistry and transport model, J. Geophys. Res., 107, 41414157, doi:10.1029/2001JD000455, 2002.

Liu, X. H., Penner, J. E., and Herzog, M.: Global modeling of aerosol dynamics: Model description, evaluation, and interactions between sulfate and nonsulfate aerosols, J. Geophys. Res., 110, D18206, doi:10.1029/2004jd005674, 2005.

Myriokefalitakis, S., Tsigaridis, K., Mihalopoulos, N., Sciare, J., Nenes, A., Kawamura, K., Segers, A., and Kanakidou, M.: Incloud oxalate formation in the global troposphere: a 3-D modeling study, Atmos. Chem. Phys., 11, 5761-5782, doi:10.5194/acp11-5761-2011, 2011.

Ng, N. L., Chhabra, P. S., Chan, A. W. H., Surratt, J. D., Kroll, J. H., Kwan, A. J., McCabe, D. C., Wennberg, P. O., Sorooshian, A., Murphy, S. M., Dalleska, N. F., Flagan, R. C., and Seinfeld, J. H.: Effect of $\mathrm{NO}_{\mathrm{x}}$ level on secondary organic aerosol (SOA) formation from the photooxidation of terpenes, Atmos. Chem. Phys., 7, 5159-5174, doi:10.5194/acp-7-5159-2007, 2007.

Ng, N. L., Canagaratna, M. R., Zhang, Q., Jimenez, J. L., Tian, J., Ulbrich, I. M., Kroll, J. H., Docherty, K. S., Chhabra, P. S., Bahreini, R., Murphy, S. M., Seinfeld, J. H., Hildebrandt, L., Donahue, N. M., DeCarlo, P. F., Lanz, V. A., Prévôt, A. S. H., Dinar, E., Rudich, Y., and Worsnop, D. R.: Organic aerosol components observed in Northern Hemispheric datasets from Aerosol Mass Spectrometry, Atmos. Chem. Phys., 10, 46254641, doi:10.5194/acp-10-4625-2010, 2010.

Odum, J. R., Hoffmann, T., Bowman, F., Collins, D., Flagan, R. C., and Seinfeld, J. H.: Gas/particle partitioning and secondary organic aerosol yields, Environ. Sci. Technol., 30, 2580-2585, 1996.

Pandis, S. N. and Seinfeld, J. H.: Sensitivity analysis of a chemical mechanism for aqueous-phase atmospheric chemistry, J. Geophys. Res., 94, 1105-1126, doi:10.1029/JD094iD01p01105, 1989.

Pankow, J. F.: An absorption model of gas/particle partitioning of organic compounds in the atmosphere, Atmos. Environ., 28, 185-188, doi:10.1016/1352-2310(94)90093-0, 1994.

Paulot, F., Crounse, J. D., Kjaergaard, H. G., Kurten, A., St Clair, J. M., Seinfeld, J. H., and Wennberg, P. O.: Unexpected Epoxide Formation in the Gas-Phase Photooxidation of Isoprene, Science, 325, 730-733, doi:10.1126/science.1172910, 2009.

Peeters, J., Nguyen, T. L., and Vereecken, L.: $\mathrm{HO}_{\mathrm{x}}$ radical regeneration in the oxidation of isoprene, Phys. Chem. Chem. Phys., 11, 5935-5939, doi:10.1039/b908511d, 2009.

Penner, J. E., Chuang, C. C., and Grant, K.: Climate forcing by carbonaceous and sulfate aerosols, Clim. Dynam., 14, 839-851, 1998.

Perri, M. J., Seitzinger, S., and Turpin, B. J.: Secondary organic aerosol production from aqueous photooxidation of glycolaldehyde: Laboratory experiments, Atmos. Environ., 43, 1487-1497, 2009.

Pye, H. O. T. and Seinfeld, J. H.: A global perspective on aerosol from low-volatility organic compounds, Atmos. Chem. Phys., 10, 4377-4401, doi:10.5194/acp-10-4377-2010, 2010.

Rinaldi, M., Decesari, S., Carbone, C., Finessi, E., Fuzzi, S., Ceburnis, D., O’Dowd, C., Sciare, J., Burrows, J., Vrekoussis, M., Ervens, B., Tsigaridis, K., and Facchini, M. C.:, Evidence of a natural marine source of oxalic acid and a possible link to glyoxal, J. Geophys. Res., 116, D16204, doi:10.1029/2011JD015659, 2011. 
Robinson, A. L., Donahue, N. M., Shrivastava, M. K., Weitkamp, E. A., Sage, A. M., Grieshop, A. P., Lane, T. E., Pierce, J. R., and Pandis, S. N.: Rethinking organic aerosols: Semivolatile emissions and photochemical aging, Science, 315, 1259-1262, doi:10.1126/science.1133061, 2007.

Robinson, N. H., Hamilton, J. F., Allan, J. D., Langford, B., Oram, D. E., Chen, Q., Docherty, K., Farmer, D. K., Jimenez, J. L., Ward, M. W., Hewitt, C. N., Barley, M. H., Jenkin, M. E., Rickard, A. R., Martin, S. T., McFiggans, G., and Coe, H.: Evidence for a significant proportion of Secondary Organic Aerosol from isoprene above a maritime tropical forest, Atmos. Chem. Phys., 11, 1039-1050, doi:10.5194/acp-11-1039-2011, 2011.

Schwartz, S. E.: Mass-transport considerations pertinent to aqueous phase reactions of gases on liquid water clouds, in Chemistry of Multiphase Atmospheric Systems, NATO ASI Ser., edited by: Jaeschke, W., Springer, Berlin, Germany, 1986.

Sillman, S.: A numerical-solution for the equations of tropospheric chemistry based on an analysis of sources and sinks of odd hydrogen, J. Geophys. Res., 96, 20735-20744, 1991.

Sillman, S., Marsik, F. J., Al-Wali, K. I., Keeler, G. J., and Landis, M. S.: Reactive mercury in the troposphere: Model formation and results for Florida, the northeastern United States, and the Atlantic Ocean, J. Geophys. Res., 112, D23305, doi:10.1029/2006JD008227, 2007.

Smith, M. L., Bertram, A. K., and Martin, S. T.: Deliquescence, efflorescence, and phase miscibility of mixed particles of ammonium sulfate and isoprene-derived secondary organic material, Atmos. Chem. Phys., 12, 9613-9628, doi:10.5194/acp-12-96132012, 2012.

Sorooshian, A., Brechtel, F. J., Ervens, B., Feingold, G., Varutbangkul, V., Bahreini, R., Murphy, S., Holloway, J. S., Atlas, E. L., Anlauf, K., Buzorius, G., Jonsson, H., Flagan, R. C., and Seinfeld, J. H.: Oxalic acid in clear and cloudy atmospheres: Analysis of data from International Consortium for Atmospheric Research on Transport and Transformation 2004, J. Geophys. Res., 111, D23S45, doi:10.1029/2005JD006880, 2006.

Sorooshian, A., Lu, M. L., Brechtel, F. J., Jonsson, H., Feingold, G., Flagan, R. C., and Seinfeld, J. H.: On the source of organic acid aerosol layers above clouds, Environ. Sci. Technol., 41, 46474654, 2007.

Sorooshian, A., Wang, Z., Coggon, M. M., Jonsson, H. H., and Ervens, B.: Observations of Sharp Oxalate Reductions in Stratocumulus Clouds at Variable Altitudes: Organic Acid and Metal Measurements During the 2011 E-PEACE Campaign, Environ. Sci. Technol., 47, 147747-147756, doi:10.1021/es4012383, 2013.

Spracklen, D. V., Jimenez, J. L., Carslaw, K. S., Worsnop, D. R., Evans, M. J., Mann, G. W., Zhang, Q., Canagaratna, M. R., Allan, J., Coe, H., McFiggans, G., Rap, A., and Forster, P.: Aerosol mass spectrometer constraint on the global secondary organic aerosol budget, Atmos. Chem. Phys., 11, 12109-12136, doi:10.5194/acp-11-12109-2011, 2011.

Stavrakou, T., Müller, J.-F., De Smedt, I., Van Roozendael, M., Kanakidou, M., Vrekoussis, M., Wittrock, F., Richter, A., and Burrows, J. P.: The continental source of glyoxal estimated by the synergistic use of spaceborne measurements and inverse modelling, Atmos. Chem. Phys., 9, 8431-8446, doi:10.5194/acp-98431-2009, 2009.
Stroud, C. A., Makar, P. A., Moran, M. D., Gong, W., Gong, S., Zhang, J., Hayden, K., Mihele, C., Brook, J. R., Abbatt, J. P. D., and Slowik, J. G.: Impact of model grid spacing on regionaland urban- scale air quality predictions of organic aerosol, Atmos. Chem. Phys., 11, 3107-3118, doi:10.5194/acp-11-31072011, 2011.

Sundqvist, H., Berge, E., and Kristjánsson, J. E.: Condensation and Cloud Parameterization Studies with a Mesoscale Numerical Weather Prediction Model, Mon. Weather Rev., 117, 1641-1657, 1989.

Surratt, J. D., Chan, A. W. H., Eddingsaas, N. C., Chan, M. N., Loza, C. L., Kwan, A. J., Hersey, S. P., Flagan, R. C., Wennberg, P. O., and Seinfeld, J. H.: Reactive intermediates revealed in secondary organic aerosol formation from isoprene, P. Natl. Acad. Sci. USA, 107, 6640-6645, doi:10.1073/pnas.0911114107, 2010.

Talbot, R. W., Andreae, M. O., Andreae, T. W., and Harriss, R. C.: Regional aerosol chemistry of the Amazon Basin during the dry season, J. Geophys. Res., 93, 1499, doi:10.1029/JD093iD02p01499, 1988.

Tan, Y., Perri, M. J., Seitzinger, S. P., and Turpin, B. J.: Effects of Precursor Concentration and Acidic Sulfate in Aqueous Glyoxal-OH Radical Oxidation and Implications for Secondary Organic Aerosol, Environ. Sci. Technol., 43, 8105-8112, doi:10.1021/es901742f, 2009.

Tan, Y., Carlton, A. G., Seitzinger, S. P., and Turpin, B. J.: SOA from methylglyoxal in clouds and wet aerosols: Measurement and prediction of key products, Atmos. Environ., 44, 5218-5226, 2010.

Tan, Y., Lim, Y. B., Altieri, K. E., Seitzinger, S. P., and Turpin, B. J.: Mechanisms leading to oligomers and SOA through aqueous photooxidation: insights from $\mathrm{OH}$ radical oxidation of acetic acid and methylglyoxal, Atmos. Chem. Phys., 12, 801-813, doi:10.5194/acp-12-801-2012, 2012.

Taylor, S. R. and McLennan S. M.: The Continental Crust: Its Composition and Evolution, 312 pp., Blackwell Sci., Oxford, UK, 1985.

Volkamer, R., Jimenez, J. L., San Martini, F., Dzepina, K., Zhang, Q., Salcedo, D., Molina, L. T., Worsnop, D. R., and Molina, M. J.: Secondary organic aerosol formation from anthropogenic air pollution: Rapid and higher than expected, Geophys. Res. Lett., 33, L17811, doi:10.1029/2006GL026899, 2006.

Volkamer, R., Ziemann, P. J., and Molina, M. J.: Secondary Organic Aerosol Formation from Acetylene $\left(\mathrm{C}_{2} \mathrm{H}_{2}\right)$ : seed effect on SOA yields due to organic photochemistry in the aerosol aqueous phase, Atmos. Chem. Phys., 9, 1907-1928, doi:10.5194/acp9-1907-2009, 2009.

Wang, M., Penner, J. E., and Liu, X.: Coupled IMPACT aerosol and NCAR CAM3 model: Evaluation of predicted aerosol number and size distribution, J. Geophys. Res., 114, D06302, doi:10.1029/2008JD010459, 2009.

Warneck, P.: In-cloud chemistry opens pathway to the formation of oxalic acid in the marine atmosphere, Atmos. Environ., 37, 2423-2427, doi:10.1016/S1352-2310(03)00136-5, 2003.

Waxman, E. M., Dzepina, K., Ervens, B., Lee-Taylor, J., Aumont, B., Jimenez, J. L., Madronich, S., and Volkamer, R.: Secondary organic aerosol formation from semi- and intermediate-volatility organic compounds and glyoxal: Relevance of $\mathrm{O} / \mathrm{C}$ as a tracer 
for aqueous multiphase chemistry, Geophys. Res. Lett., 40, 978982, doi:10.1002/grl.50203, 2013.

Wonaschuetz, A., Sorooshian, A., Ervens, B., Chuang, P. Y., Feingold, G., Murphy, S. M., de Gouw, J., Warneke, C., and Jonsson, H. H.: Aerosol and gas redistribution by shallow cumulus clouds: An investigation using airborne measurements, J. Geophys. Res., 117, D17202, doi:10.1029/2012jd018089, 2012.

Xing, L., Fu, T.-M., Cao, J. J., Lee, S. C., Wang, G. H., Ho, K. F., Cheng, M.-C., You, C.-F., and Wang, T. J.: Seasonal and spatial variability of the $\mathrm{OM} / \mathrm{OC}$ mass ratios and high regional correlation between oxalic acid and zinc in Chinese urban organic aerosols, Atmos. Chem. Phys., 13, 4307-4318, doi:10.5194/acp13-4307-2013, 2013.

$\mathrm{Xu}, \mathrm{K} .-\mathrm{M}$. and Krueger, S. K.: Evaluation of Cloudiness Parameterizations Using a Cumulus Ensemble Model, Mon. Weather Rev., $119,342-367,1991$.
Xu, L. and Penner, J. E.: Global simulations of nitrate and ammonium aerosols and their radiative effects, Atmos. Chem. Phys., 12, 9479-9504, doi:10.5194/acp-12-9479-2012, 2012.

Zhang, Q., Jimenez, J. L., Canagaratna, M. R., Allan, J. D., Coe, H., Ulbrich, I., Alfarra, M. R., Takami, A., Middlebrook, A. M., Sun, Y. L., Dzepina, K., Dunlea, E., Docherty, K., DeCarlo, P. F., Salcedo, D., Onasch, T., Jayne, J. T., Miyoshi, T., Shimono, A., Hatakeyama, S., Takegawa, N., Kondo, Y., Schneider, J., Drewnick, F., Borrmann, S., Weimer, S., Demerjian, K., Williams, P., Bower, K., Bahreini, R., Cottrell, L., Griffin, R. J., Rautiainen, J., Sun, J. Y., Zhang, Y. M., and Worsnop, D. R.: Ubiquity and dominance of oxygenated species in organic aerosols in anthropogenically-influenced Northern Hemisphere midlatitudes, Geophys. Res. Lett., 34, L13801, doi:10.1029/2007GL029979, 2007. 